\title{
Anti-Inflammatory Effects of Traditional Chinese Medicines against Ischemic Injury in In Vivo Models of Cerebral Ischemia
}

\author{
Chin-Yi Cheng ${ }^{1,2}$ and Yu-Chen Lee ${ }^{3,4,5}$ \\ ${ }^{1}$ School of Chinese Medicine, College of Chinese Medicine, China Medical University, Taichung 40402, Taiwan \\ ${ }^{2}$ Department of Chinese Medicine, Hui-Sheng Hospital, Taichung 42056, Taiwan \\ ${ }^{3}$ Department of Chinese Medicine, China Medical University Hospital, Taichung 40447, Taiwan \\ ${ }^{4}$ Research Center for Chinese Medicine \& Acupuncture, China Medical University, Taichung 40402, Taiwan \\ ${ }^{5}$ Graduate Institute of Acupuncture Science, China Medical University, Taichung 40402, Taiwan
}

Correspondence should be addressed to Yu-Chen Lee; d5167@mail.cmuh.org.tw

Received 22 May 2016; Accepted 25 July 2016

Academic Editor: Xiang Liu

Copyright $\odot 2016$ C.-Y. Cheng and Y.-C. Lee. This is an open access article distributed under the Creative Commons Attribution License, which permits unrestricted use, distribution, and reproduction in any medium, provided the original work is properly cited.

\begin{abstract}
Inflammation plays a crucial role in the pathophysiology of acute ischemic stroke. In the ischemic cascade, resident microglia are rapidly activated in the brain parenchyma and subsequently trigger inflammatory mediator release, which facilitates leukocyteendothelial cell interactions in inflammation. Activated leukocytes invade the endothelial cell junctions and destroy the bloodbrain barrier integrity, leading to brain edema. Toll-like receptors (TLRs) stimulation in microglia/macrophages through the activation of intercellular signaling pathways secretes various proinflammatory cytokines and enzymes and then aggravates cerebral ischemic injury. The secreted cytokines activate the proinflammatory transcription factors, which subsequently regulate cytokine expression, leading to the amplification of the inflammatory response and exacerbation of the secondary brain injury. Traditional Chinese medicines (TCMs), including TCM-derived active compounds, Chinese herbs, and TCM formulations, exert neuroprotective effects against inflammatory responses by downregulating the following: ischemia-induced microglial activation, microglia/macrophage-mediated cytokine production, proinflammatory enzyme production, intercellular adhesion molecule-1, matrix metalloproteinases, TLR expression, and deleterious transcription factor activation. TCMs also aid in upregulating antiinflammatory cytokine expression and neuroprotective transcription factor activation in the ischemic lesion in the inflammatory cascade during the acute phase of cerebral ischemia. Thus, TCMs exert potent anti-inflammatory properties in ischemic stroke and warrant further investigation.
\end{abstract}

\section{Introduction}

Stroke is the third leading cause of death in developed countries [1] and the major cause of severe long-term disability worldwide [1-3]. Approximately 15 million people experience stroke annually. Of these, one-third die and one-third experience permanent disabilities, thus imposing considerable social and economic burden [4]. Approximately 80\%-85\% of all stroke events are ischemic caused by cerebral arterial thrombosis or embolism $[5,6]$. To date, recombinant tissue plasminogen activator (rtPA) is the only Food and Drug Administration-approved medical therapy for acute ischemic stroke. However, rtPA has severe disadvantages, including the narrow therapeutic time window of $4.5 \mathrm{~h}$ and potential risk of hemorrhagic transformation; therefore, the eligibility of rtPA is reduced to only $4 \%-7 \%$ in all the patients with acute ischemic stroke [5]. Thus, potential therapeutic strategies for ischemic stroke are urgently needed.

Increasing evidence has demonstrated that inflammation plays a pivotal role in the pathophysiology of acute ischemic stroke $[3,5,7]$. During acute ischemic stroke, the brain is injured by ischemia- and inflammation-related primary and secondary insults [5]. The primary injury occurs at the beginning of ischemia; it rapidly interrupts the cerebral blood flow to the ischemic core and subsequently causes a significant decrease in oxygen and glucose supply to 
cerebral neurons $[8,9]$. The secondary injury is attributed to the postischemic inflammatory cascade, which produces various proinflammatory mediators, including cytokines, chemokines, proteases, and cell adhesion molecules, leading to an exacerbated ischemic brain injury [10]. However, the postischemic inflammatory response has a disadvantage and an advantage, exacerbating ischemic brain damage in the early phase and triggering tissue regeneration in the delayed phase, respectively $[1,2]$.

The lack of effective and widely applicable therapeutic strategies for the treatment of ischemic stroke has triggered increasing interest in traditional medicines, particularly traditional Chinese medicine (TCM) [11, 12]. Several centuries ago, TCM was used in China to treat cerebrovascular disorders, including stroke. Evidence revealed that TCM preparation, Chinese herb medicine, and TCM-derived active compounds exert anti-inflammatory effects by inhibiting inflammatory mediators, leukocyte infiltration, and bloodbrain barrier (BBB) disruption in experimental cerebral ischemia [13]. These potent effects of TCMs against cerebral ischemic injury highlight their potential in clinical applications. Therefore, this review summarized the origin and development of the postischemic inflammatory cascade and delineated the anti-inflammatory effects of TCMs (namely, TCM-derived active compounds, Chinese herbs, and TCM formulations) on the basis of the in vivo literature.

\section{TCM-Mediated Downregulation of Microglial Activation}

2.1. Activation of Microglia in the Initial Phase of Cerebral Ischemia. In the acute phase ( $\mathrm{min}$ to $\mathrm{h}$ ) of cerebral ischemia, ischemic injury triggers a rapid activation of resident microglia in the brain parenchyma [3, 14]. During cerebral ischemia, microglial morphology changes from a ramified to an amoeboid shape upon activation [15]. In the initial stage of ischemia, the injured neurons expose damage-associated molecular patterns (DAMPs), which are subsequently recognized by toll-like receptors (TLRs), such as TLR4, and other pattern recognition receptors on the surface of the reactive microglia; this recognition triggers microgliamediated inflammatory mediators release, contributing to secondary damage after stroke $[6,10,16]$. Reactive microglia/ macrophages can be detected as early as $2 \mathrm{~h}$ after cerebral ischemia and maintained up to 1 week after the ischemic insult [6]. Reactive microglia are divided into two phenotypes: the classically and alternatively activated phenotypes (M1 and M2, resp.) [17]. The M1 microglia produce proinflammatory mediators, such as cytokines [interleukin- (IL) $1 \beta$, IL-6, IL-18, and tumor necrosis factor- (TNF-) $\alpha$, chemokines [monocyte chemoattractant protein- (MCP-) 1 , and macrophage inflammatory protein- (MIP-) $1 \alpha]$, interferon- (IFN-) $\gamma$, matrix metalloproteinase- (MMP-) 9, and reactive oxygen species (ROS) [18], exerting detrimental functions in the early phase. By contrast, the M2 microglia secrete anti-inflammatory mediators, such as IL-4, IL-10, IL13 , transforming growth factor- (TGF-) $\beta$, and insulin growth factor-1, exerting neuroprotective effects in the delayed phase $[2,3,19]$. In cerebral ischemia, microglial activation is accompanied by reactive astrogliosis, which also produces an excessive amount of cytokines and causes the exacerbation of ischemic brain injury [18].

2.2. The Effects and Mechanisms of TCMs on Inhibiting Microglial Activation in In Vivo Models of Cerebral Ischemia. Hsieh et al. reported that Paeonol, a common compound of Paeonia suffruticosa Andrews (Chinese name, Mu Dan $\mathrm{Pi}$; Moutan cortex), reduces cerebral infarct and neurological deficits at $1.5 \mathrm{~h}$ of ischemia and $24 \mathrm{~h}$ of reperfusion. Paeonol exerts anti-infarct effect mainly by inhibiting microglial activation and IL-1 $\beta$ expression in the ischemic cortex in ischemia/reperfusion- (I/R-) injured rats [20]. Pretreatment with tetramethylpyrazine (TMP), an active compound isolated from Ligusticum wallichii Franch (Chuan Xiong), effectively reduces the cerebral volume by inhibiting myeloperoxidase (an inflammation marker) and ED1 (a microglia/macrophage marker) expression in the ischemic core $72 \mathrm{~h}$ after reperfusion. The effect of TMP against microglial activation-mediated neurotoxicity can be further attributed to the suppression of prostaglandin E2 (PGE2) in the ischemic core [21]. A later study reported that TMP provides neuroprotection against ischemic brain injury partially by inhibiting microglial activation and subsequently downregulating MCP-1 expression in the ischemic cortex $72 \mathrm{~h}$ after reperfusion [22]. Andrographolide, the major active compound derived from Andrographis paniculata (Chuan Xin Lian) protects against cerebral infarction and ameliorates neurological deficits $24 \mathrm{~h}$ after permanent middle cerebral artery occlusion (MCAo). Andrographolide exerts neuroprotective effects partially by inhibiting microglial activation and microglia-mediated IL- $1 \beta$ and TNF- $\alpha$ expression in the ischemic area [23]. Pretreatment with Sophora japonica L. (Huai Hua; intraperitoneal injection) effectively reduced the cerebral infarct area and neurological deficits at $1.5 \mathrm{~h}$ of ischemia and $24 \mathrm{~h}$ of reperfusion. The effects of $S$. japonica involve the suppression of microglial activation and microglia-mediated IL- $1 \beta$ expression in the ischemic cortex [24]. Lim et al. demonstrated that an intragastric administration of total isoflavones isolated from Pueraria lobata (Ge Gen; TIPL) significantly reduces the cerebral infarct volume at $2 \mathrm{~h}$ of ischemia and $48 \mathrm{~h}$ of reperfusion. The anti-inflammatory effect of TIPL is partially attributed to the inhibition of astrocyte and microglial activation in the hippocampal CA1 region $7 \mathrm{~d}$ after MCAo [25].

On the basis of these studies, the anti-inflammatory effects of TCMs against cerebral ischemic injury could be attributed to the downregulation of microglial activation and microglia-mediated proinflammatory cytokines production in the ischemic area during the initial phase of MCAo (Figure 1 and Table 1).

\section{TCM-Mediated Suppression of Leukocyte Infiltration}

3.1. The Process of Leukocyte Infiltration during Cerebral Ischemia. The microglial and astrocytic production of proinflammatory mediators rapidly increase the expression of 


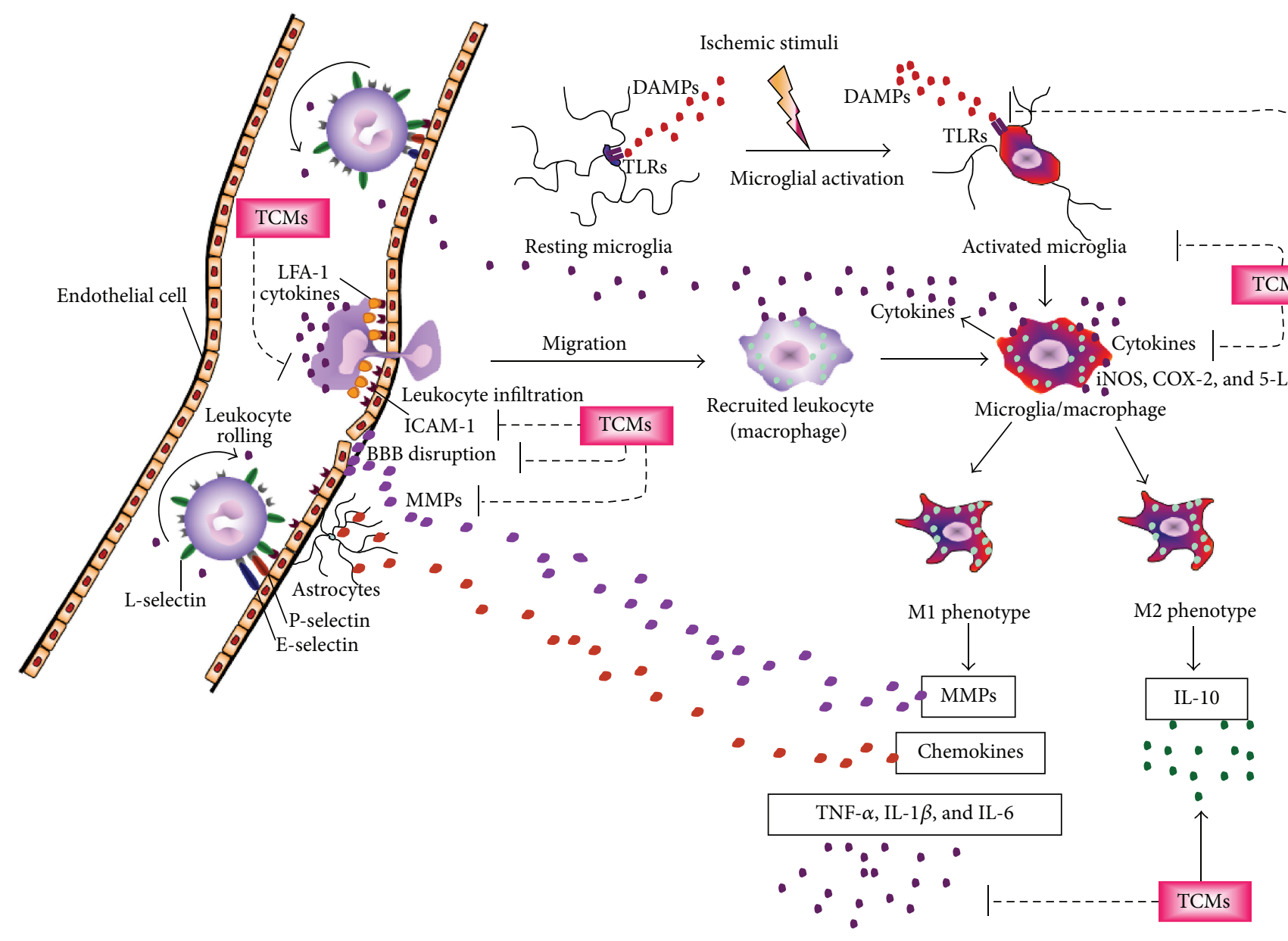

FIGURE 1: Schematic representation of the effects of traditional Chinese medicines on inflammation responses in the inflammatory cascade after cerebral ischemia. TCMs, traditional Chinese medicines; DAMPs, damage-associated molecular patterns; TLRs, toll-like receptors; LFA1, leukocyte function-associated antigen-1 (CD11a/CD18); ICAM-1, intercellular adhesion molecule-1; MMPs, matrix metalloproteinases; iNOS, inducible nitric oxide synthase; COX-2, cyclooxygenase-2; 5-LO, 5-lipoxygenase; BBB, blood-brain barrier. Thick solid lines with arrowheads indicate activation, and thin dotted lines indicate inhibition.

adhesion molecules on the endothelium [26, 27]. During acute cerebral I/R injury, the peripheral leukocytes first roll, become activated, and consequentially attach to the endothelial cells in the ischemic lesion. Leukocyteendothelial cell interactions in inflammation are mediated by various adhesion molecules, including selectins, integrins, intercellular adhesion molecule- (ICAM-) 1, and vascular cell adhesion molecule-1 [28]. Selectins, comprising L-selectin on leukocytes and E- and P-selectins on endothelial cells, are a family of lectin-like adhesion glycoproteins that regulate leukocyte rolling and recruitment $[28,29]$. Integrins, including leukocyte function-associated antigen-1 (CD11a/CD18) expressed on all leukocytes and macrophage-1 (MAC-1; CD11b/CD18) expressed on neutrophils and monocytes, are transmembrane glycoproteins and mediate leukocyteendothelium interactions [30]. In acute cerebral ischemia, the upregulation of integrins facilitates a firm adherence of leukocytes to endothelial ICAM-1; the leukocytes subsequently penetrate the endothelial basement membrane into the brain parenchyma. Thus, the tight junctions (TJs) between endothelial cells of the $\mathrm{BBB}$ are disrupted and become more permeable, leading to leukocyte infiltration [30]. This evidence revealed that circulating leukocytes adhere to the damaged endothelium as early as $4 \mathrm{~h}$ and achieve the peak at approximately $12-48 \mathrm{~h}$ after ischemic brain injury. Meanwhile, reactive microglia, platelets, and infiltrating leukocytes further release IL- $1 \beta$, IL-6, TNF- $\alpha$, ROS, MCP-1, MIP-1 $\alpha$, IL-8, and MMPs (mainly MMP-9) that exacerbate ischemic injury in MCAo $[3,5,6]$.

3.2. The Effects and Mechanisms of TCMs on Inhibiting Leukocyte Infiltration in In Vivo Models of Cerebral Ischemia. $\mathrm{Lu}$ et al. reported that emodin, an active component of the rhizome of Rheum palmatum L. (Da Huang), effectively reduces the cerebral infarct size $6 \mathrm{~h}$ after MCAo. The neuroprotective effects of emodin can be attributed to ICAM1 downregulation in the ischemic area in the early phase of cerebral ischemia [31]. Ferulic acid (FA), a major active compound in both Angelica sinensis (Oliv.) Diels (Dang Gui) 
TABLE 1: TCMs downregulate microglial activation in the inflammatory cascade in ischemic stroke models.

\begin{tabular}{|c|c|c|c|c|}
\hline TCMs & $\begin{array}{l}\text { Isolated from the Chinese } \\
\text { herb (Chinese name) }\end{array}$ & $\begin{array}{l}\text { Anti-inflammatory } \\
\text { actions }\end{array}$ & Models & References \\
\hline Paeonol & Mu Dan & ED1 $\downarrow$, IL-1 $\beta \downarrow$ & $\begin{array}{c}\text { MCAo } \\
1.5 \mathrm{~h} \text { of ischemia followed by } \\
24 \mathrm{~h} \text { of reperfusion }\end{array}$ & {$[20]$} \\
\hline Tetramethylpyrazine & Chuan Xiong & MPO $\downarrow$, ED1 $\downarrow$, PGE $2 \downarrow$ & $\begin{array}{c}\text { MCAo } \\
1.5 \mathrm{~h} \text { of ischemia followed by } \\
72 \mathrm{~h} \text { of reperfusion }\end{array}$ & {$[21]$} \\
\hline Tetramethylpyrazine & Chuan Xiong & MCP-1 1 & $\begin{array}{c}\text { MCAo } \\
1.5 \mathrm{~h} \text { of ischemia followed by } \\
72 \mathrm{~h} \text { of reperfusion }\end{array}$ & {$[22]$} \\
\hline Andrographolide & Chuan Xin Lian & $\begin{array}{l}\text { NF- } \kappa \text { Bp } 65 \downarrow, \text { TNF- } \alpha \downarrow \text {, } \\
\text { IL-1 } \beta \downarrow, \text { PGE } 2 \downarrow\end{array}$ & $\begin{array}{c}\text { Permanent MCAo } \\
24 \mathrm{~h} \text { of ischemia }\end{array}$ & {$[23]$} \\
\hline Sophora japonica L & Huai Hua & $\mathrm{ED} 1 \downarrow, \mathrm{IL}-1 \beta \downarrow$ & $\begin{array}{c}\text { MCAo } \\
1.5 \mathrm{~h} \text { of ischemia followed by } \\
24 \mathrm{~h} \text { of reperfusion }\end{array}$ & {$[24]$} \\
\hline Isoflavones & Ge Gen & $\begin{array}{l}\mathrm{COX}-2 \downarrow, \mathrm{GFAP} \downarrow \\
\mathrm{OX}-42 \downarrow\end{array}$ & $\begin{array}{c}\text { MCAo } \\
\begin{array}{c}2 \mathrm{~h} \text { of ischemia followed by } 2 \\
\text { or } 7 \mathrm{~d} \text { of reperfusion }\end{array}\end{array}$ & {$[25]$} \\
\hline
\end{tabular}

ED1, CD68 (macrophage marker); MPO, myeloperoxidase; PGE2, prostaglandin E2; MCP-1, monocyte chemoattractant protein-1; COX-2, cyclooxygenase-2; GFAP, glial fibrillary acidic protein; OX-42, CD11b (microglial activation marker).

and Ligusicum chuanxiong Hort. (Chuan Xiong), effectively reduces the cerebral infarct area and ameliorates the neurological deficit at $1.5 \mathrm{~h}$ of reperfusion and $24 \mathrm{~h}$ of reperfusion. FA exerts anti-inflammatory effects against cerebral I/R injury, at least partially, by inhibiting ICAM-1, mRNA, and Mac-1 mRNA expression in the ischemic striatum $2 \mathrm{~h}$ after reperfusion [32, 33]. Bu-yang Huan-wu decoction (BHD), composed of Astragalus membranaceus Bunge (Huang Qi), A. sinensis (Oliv.) Diels (Dang Gui), Paeonia lactiflora Pall (Shao Yao), L. chuanxiong (Chuan Xiong), Prunus persica (L.) Batsch (Tao Ren), Carthamus tinctorius L. (Hong Hua), and Pheretima aspergillum (Di Long), effectively ameliorates cerebral infarction and improves neurological deficits $24 \mathrm{~h}$ after transient MCAo. The effects of BHD against cerebral ischemic injury are partially attributed to the inhibition of CD1lb (a marker of leukocyte and monocyte activation) expression in the ischemic area [34]. Persimmon leaf flavonoid isolated from Diospyros kaki L.F (Shi Zhi Ye) exerts anti-inflammatory effects by downregulating ICAM1 expression in the ischemic area $2 \mathrm{~h}$ after cerebral ischemia and $24 \mathrm{~h}$ after reperfusion [35]. Liu et al. demonstrated that the oral administration of Cordyceps sinensis (Dong Chong Xia Cao) mycelium exerts neuroprotective effects against cerebral I/R injury by downregulating ICAM-1, IL-1 $\beta$, and TNF- $\alpha$ expression and infiltrating polymorphonuclear leukocytes (PMNs) in the ischemic area $2 \mathrm{~h}$ after ischemia and $22 \mathrm{~h}$ after reperfusion [12]. The oral pretreatment with a herb formula, FuLing-BaiZhu-DangGui (FBD), composed of Poria cocos (Fu Ling), Atractylodes macrocephala (Bai Zhu), and $A$. sinensis, protects against cerebral I/R injury partially by inhibiting PMNs infiltration in the ischemic area $24 \mathrm{~h}$ after transient forebrain ischemia in mice. The anti-inflammatory properties of FBD can be further attributed to IL-1 $\beta$, TNF- $\alpha$, and IL- 8 downregulation during the acute phase of cerebral ischemia [36]. Kong et al. reported that Borneol (Bing Pian), the resin of Dryobalanops aromatica Gaertn. F., effectively improves neurological deficits $24 \mathrm{~h}$ after forebrain ischemia. The beneficial effects of Borneol involve the reduction of leukocyte infiltration and ICAM-1 expression in the ischemic area [37].

These results indicate that TCMs provide beneficial effects against leukocyte infiltration mainly by downregulating ICAM-1 expression and activated leukocyte-induced cytokines, such as IL-1 $\beta$, TNF- $\alpha$, and IL- 8 , in the ischemic lesion in the acute phase of cerebral ischemia (Figure 1 and Table 2).

\section{TCM-Mediated Stabilization of Blood-Brain Barrier Integrity}

4.1. Blood-Brain Barrier Disruption during Cerebral Ischemia. Under normal conditions, leukocyte recruitment across the $\mathrm{BBB}$ into the brain parenchyma contributes to the maintenance of the central nervous system immune privilege [9]. The BBB comprising endothelial cells, the basement membrane, the astrocyte end-feet, and pericytes provides a highly selective permeability barrier that separates the blood cells from the brain interstitial fluid and maintains brain homeostasis [38]. However, during the acute phase of cerebral ischemia, the infiltrated leukocytes and reactive microglia synthesize and secrete MMPs (mainly MMP-2 and MMP-9) and ROS, thus increasing BBB permeability [72, 73]. Previous studies have reported that MMP-9 activation is initiated as early as $4 \mathrm{~h}$, which reaches the maximum level at $24 \mathrm{~h}$ and persists for at least $5 \mathrm{~d}$ after cerebral ischemia $[74,75]$, whereas activated MMP-2 reaches the highest level $5 \mathrm{~d}$ after MCAo [75]. Active MMPs disrupt BBB integrity by degrading the 
TABLE 2: TCMs suppress leukocyte infiltration in the inflammatory cascade in ischemic stroke models.

\begin{tabular}{|c|c|c|c|c|}
\hline TCMs & $\begin{array}{c}\text { Isolated from the Chinese } \\
\text { herb (Chinese name) }\end{array}$ & Anti-inflammatory actions & Models & References \\
\hline Emodin & Da Huang & ICAM- $1 \downarrow$, TNF- $\alpha \downarrow$, IL- $1 \beta \downarrow$ & $\begin{array}{c}\text { MCAo } \\
6 \mathrm{~h} \text { of ischemia }\end{array}$ & {$[31]$} \\
\hline Ferulic acid & Dang Gui or Chuan Xiong & $\begin{array}{l}\text { ICAM-1 } \downarrow \text {, ICAM-1 } \\
\text { mRNA } \downarrow, \text { MPO } \downarrow, \\
\text { NF- } \kappa \text { Bp50 } \downarrow,\end{array}$ & $\begin{array}{c}\text { MCAo } \\
1.5 \mathrm{~h} \text { of ischemia followed } \\
\text { by } 2 \text { or } 24 \mathrm{~h} \text { of reperfusion }\end{array}$ & {$[32,33]$} \\
\hline $\begin{array}{l}\text { Bu-yang Huan-wu } \\
\text { decoction }\end{array}$ & $\begin{array}{l}\text { Huang Qi, Dang Gui, Shao } \\
\text { Yao, Chuan Xiong, Tao } \\
\text { Ren, Hong Hua, Di Long }\end{array}$ & $\mathrm{CD} 11 \mathrm{~b} \downarrow$ & $\begin{array}{c}\text { MCAo } \\
0.5 \mathrm{~h} \text { of ischemia followed } \\
\text { by } 24 \mathrm{~h} \text { of reperfusion }\end{array}$ & {$[34]$} \\
\hline Persimmon leaf flavonoid & Shi Zhi Ye & ICAM-1 $\downarrow$ & $\begin{array}{c}\text { MCAo } \\
2 \mathrm{~h} \text { of ischemia followed by } \\
24 \mathrm{~h} \text { of reperfusion }\end{array}$ & {$[35]$} \\
\hline Cordyceps sinensis & Dong Chong Xia Cao & $\begin{array}{c}\text { ICAM- } 1 \downarrow, \text { TNF- } \alpha \downarrow \text {, IL- } 1 \beta \downarrow \\
\text { NF- } \kappa \text { Bp } 50 \downarrow \text {, iNOS } \downarrow \\
\text { COX- } 2 \downarrow\end{array}$ & $\begin{array}{c}\text { MCAo } \\
2 \mathrm{~h} \text { of ischemia followed by } \\
22 \mathrm{~h} \text { of reperfusion }\end{array}$ & {$[12]$} \\
\hline FuLing-BaiZhu-DangGui & Fu Ling, Bai Zhu, Dang Gui & $\begin{array}{l}\text { TNF- } \alpha \downarrow, \text { IL- } 1 \beta \downarrow, \text { IL- } 8 \downarrow \text {, } \\
\quad \text { MPO } \downarrow, \text { NF- } \kappa \text { B } \downarrow\end{array}$ & $\begin{array}{c}\text { Repetitive BCCAo } \\
10 \text { min of ischemia (repeat } 2 \\
\text { times) followed by } 24 \mathrm{~h} \text { of } \\
\text { reperfusion }\end{array}$ & {$[36]$} \\
\hline Borneol & Bing Pian & ICAM- $1 \downarrow$, TNF- $\alpha \downarrow$ & $\begin{array}{c}\text { MCAo } \\
2 \mathrm{~h} \text { of ischemia followed by } \\
22 \mathrm{~h} \text { of reperfusion }\end{array}$ & {$[37]$} \\
\hline
\end{tabular}

ICAM-1, intercellular adhesion molecule-1; BCCAo, bilateral common carotid artery occlusion.

extracellular matrix and TJs in endothelial cells and result in vascular and $\mathrm{BBB}$ leakage. The $\mathrm{BBB}$ disruption facilitates the entry of circulating leukocytes and intravascular fluid into the brain, which cause vasogenic edema and hemorrhagic transformation, leading to the exacerbation of cerebral infarction $[6,9,76]$. TJs, including claudin-5, occludin, and zonula occludens- (ZO-) 1, play a pivotal role in maintaining the structural and functional integrity of the BBB [77]. Previous studies have reported that decreased claudin-5, occludin, and ZO-1 expression is closely related to $\mathrm{BBB}$ disruption and ischemic brain edema formation [77, 78]. Thus, MMPs, claudin-5, occludin, and ZO-1 could present the potential targets for pharmacological intervention to stabilize $\mathrm{BBB}$ integrity in cerebral ischemic injury and the regulation of their activity may yield therapeutic effects.

\subsection{The Effects and Mechanisms of TCMs on Ameliorating} Blood-Brain Barrier Disruption in In Vivo Models of Cerebral Ischemia. Posttreatment methylophiopogonanone- (MO-) A, an active compound isolated from Ophiopogon japonicus (Mai Men Dong), effectively reduces the infarct volume and brain edema and improves neurological deficits $7 \mathrm{~d}$ after transient MCAo. The results indicate that MO-A protects against cerebral I/R injury mainly through its property to ameliorate $\mathrm{BBB}$ disruption through MMP-9 downregulation, and claudin-3 and claudin-5 upregulation in the ischemic cortex [38]. Tan et al. reported that pretreatment with ligustrazine, an active ingredient of $L$. wallichii Franchat (Chuan Xiong), effectively preserves BBB integrity by downregulating MMP-9 expression and upregulating claudin-5 and occludin expression in the ischemic area in a rat model of focal cerebral I/R injury [39]. Levo-tetrahydropalmatine (1-THP), a major active ingredient of Rhizoma corydalis (Yan $\mathrm{Hu}$ Suo), protects against cerebral I/R-induced BBB injury at $1.5 \mathrm{~h}$ of ischemia and $24 \mathrm{~h}$ of reperfusion. The protective effect of 1-THP can be partially attributed to MMP-2 and MMP-9 downregulation and claudin-5, occludin, and ZO-1 upregulation in the ischemic area [40].

From these results, we conclude that MMP-9 downregulation and claudin-5, occludin, and ZO-1 upregulation are the potential effects of TCMs on the stabilization of BBB integrity to ameliorate inflammatory responses in the ischemic area during the acute and subacute phases of cerebral I/R injury (Figure 1 and Table 3).

\section{TCM-Mediated Regulation of Proinflammatory Mediator Release}

5.1. Toll-Like Receptor Stimulation on Microglia/Macrophages during Cerebral Ischemia. In the ischemic core, active microglia are indistinguishable from blood-derived macrophages, and the microglia/macrophages are apparent 3.5$12 \mathrm{~h}$ after transient focal cerebral ischemia [79]. Subsequently, active microglia/macrophages are distributed in the entire middle cerebral artery territory at $22-24 \mathrm{~h}$ and maintained for up to 1 week after cerebral ischemia [6]. During cerebral ischemic insult, the dying cells release DAMPs, including heat shock proteins (HSPs), $\beta$-amyloid, hyaluronan, high mobility group box 1 (HMGB1), heparin sulfate, and ATP, thus stimulating TLRs, which are expressed on microglia/macrophages. Thereafter, the microglia/macrophages transform into M1 and M2 phenotypes upon stimulation and secrete various 
TABLE 3: TCMs stabilize blood-brain barrier integrity in the inflammatory cascade in ischemic stroke models.

\begin{tabular}{|c|c|c|c|c|}
\hline TCMs & $\begin{array}{l}\text { Isolated from the Chinese } \\
\text { herb (Chinese name) }\end{array}$ & Anti-inflammatory actions & Models & References \\
\hline Methylophiopogonanone A & Mai Men Dong & $\begin{array}{l}\text { MMP-9 } \downarrow \text {, claudin- } 3 \uparrow, \\
\text { claudin-5 }\end{array}$ & $\begin{array}{c}\text { MCAo } \\
2 \mathrm{~h} \text { of ischemia followed by } \\
7 \mathrm{~d} \text { of reperfusion }\end{array}$ & {$[38]$} \\
\hline Ligustrazine & Chuan Xiong & $\begin{array}{l}\text { MMP-9 } \downarrow \text {, claudin-5 } \\
\text { occludin } \uparrow\end{array}$ & $\begin{array}{c}\text { MCAo } \\
1.5 \mathrm{~h} \text { of ischemia followed } \\
\text { by } 22.5 \mathrm{~h} \text { of reperfusion }\end{array}$ & {$[39]$} \\
\hline Levo-tetrahydropalmatine & Yan Hu Suo & 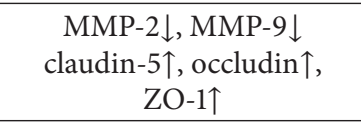 & $\begin{array}{c}\text { MCAo } \\
1.5 \mathrm{~h} \text { of ischemia followed } \\
\text { by } 24 \mathrm{~h} \text { of reperfusion }\end{array}$ & {$[40]$} \\
\hline
\end{tabular}

MMP-9, matrix metalloproteinase-9; ZO-1, zonula occludens-1.

cytokines in response to ischemic injury [73, 80, 81]. TLRs are pivotal components in the innate immune system, and TLRs (mainly TLR2 and TLR4) stimulation in microglia/ macrophages and T-lymphocytes also exerts strong regulatory effects on postischemic inflammatory responses [2, 73]. During cerebral ischemic injury, TLRs facilitate cytokine and chemokine release and trigger transcription factor activation by activating intercellular signaling pathways. According to recruitment of specific adaptors, TLR signaling can be classified into either myeloid differentiation primary response gene 88- (MyD88-) dependent or independent pathways [81]. The binding of HSPs, such as HSP60 and HSP70, or HMGB1 with TLR2 and TLR4 initiate the expression of nuclear factor(NF-) $\kappa \mathrm{B}$, TNF- $\alpha$, IL- $1 \beta$, IL- 6 , inducible nitric oxide synthase (iNOS), and ICAM-1 by activating the MyD88-dependent signaling pathway and aggravating cerebral ischemic injury [82]. TLR2 and TLR4 levels markedly increase in the ischemic brain at $6 \mathrm{~h}$, peak at $24 \mathrm{~h}$, and decline at $72 \mathrm{~h}$ after MCAo [83].

5.2. The Effects and Mechanisms of TCMs on Suppressing Toll-Like Receptor Stimulation in In Vivo Models of Cerebral Ischemia. Zhou et al. reported that the anti-infarct effects of puerarin, a major isoflavonoid in Radix puerariae (Ge Gen), can be attributed to the downregulation of TLR4/ MyD88/NF- $\kappa \mathrm{B} / \mathrm{TNF}-\alpha$ signaling in the ischemic region $24 \mathrm{~h}$ after transient MCAo [41]. TMP exerts anti-inflammatory effects against neutrophil activation $3 \mathrm{~d}$ after permanent MCAo. The beneficial effects of TMP can be partially attributed to HMGB1 and TLR4 downregulation in the ischemic cortex [42].

\subsection{M1 Microglia/Macrophages Releasing Proinflammatory} Mediators during Cerebral Ischemia. The M1 microglia/macrophages produce proinflammatory cytokines, including TNF- $\alpha$, IL-1 $\beta$, IL-6, IL-8, IL-12, IL-18, IL-20, and IFN$\gamma$, whereas the M2 microglia/macrophages release antiinflammatory cytokines, including IL-4, IL-10, IL-13, and TGF- $\beta$ [1]. TNF- $\alpha$ is a pleiotropic cytokine that possesses both neurotoxic and neuroprotective properties. In the early phase of the inflammatory response, TNF- $\alpha$ binds to TNF receptor 1 (TNFR1) and contributes to the detrimental effects, such as promoting BBB disruption, vasogenic edema, leukocyte infiltration, and endothelial cell apoptosis $[6,84$, $85]$. Furthermore, TNF- $\alpha /$ TNFR1 activates NF- $\kappa$ B signaling, which regulates the expression of cytokines; chemokines; adhesion molecules; and inducible enzymes, namely, iNOS and cyclooxygenase-2 (COX-2), thus exacerbating cerebral ischemic injury [6]. By contrast, in the late phase of postischemic inflammation, TNF- $\alpha$ /TNFR2 facilitates neuroprotection, synaptic plasticity, and tissue repair $[6,86]$. TNF- $\alpha$ becomes predominant in the ischemic lesion $24-48 \mathrm{~h}$ after MCAo [87]. IL-1, including IL- $1 \alpha$ and IL- $1 \beta$, can bind to IL-1 receptor type 1 (IL-1R1) and majorly contribute to the exacerbation of ischemic brain injury [88]. IL-1 $\beta$ has been clearly implicated in the pathogenesis of cerebral ischemia [6]. Inactive proIL- $1 \beta$ is converted to biologically active IL- $1 \beta$ by an IL- $1 \beta$-converting enzyme, which belongs to the cysteine protease family. IL- $1 \beta$ is initially upregulated at $1-3 \mathrm{~h}$ and peaks at $12-24 \mathrm{~h}$ after ischemic injury. The cytotoxic actions of IL- $1 \beta$ include facilitating the activation of microglia, infiltration of leukocytes, and production of other cytokines such as IL-6 $[6,89]$. Conversely, IL-1 receptor antagonist, a member of the IL-1 family, binds to IL-1R1 and subsequently blocks the detrimental actions of IL-1, exerting neuroprotection in cerebral ischemia process [90]. The role of IL-6 in cerebral ischemia remains controversial. Some studies have reported that IL- 6 aggravates cerebral infarction [91, 92], whereas other studies have reported the beneficial effects of IL- 6 in preventing damaged neuron from undergoing apoptosis and promoting neuronal survival after cerebral ischemia $[93,94]$. Moreover, IL-6 is predominantly expressed in the ischemic area $24-48 \mathrm{~h}$ following cerebral I/R injury [87]. IL-8, IL-12, IL-18, and IL-20 play a pivotal role in promoting cerebral ischemic injury $[7,16,95,96]$. IL-18 is initiated within $24-48 \mathrm{~h}$ and peaks at $6 \mathrm{~d}$ in the ischemic region after cerebral ischemia [97]. IFN- $\gamma$ contributes to the exacerbation of cerebral ischemia by increasing ischemiainduced glutamate release [98].

\subsection{The Effects and Mechanisms of TCMs on Downregulating} Proinflammatory Mediators in In Vivo Models of Cerebral Ischemia. Notoginseng saponins isolated from the root of Panax notoginseng (San Qi) provide beneficial effects 
against cerebral $\mathrm{I} / \mathrm{R}$ injury partially through IL- $1 \beta$ mRNA downregulation in the ischemic area after $22 \mathrm{~h}$ of reperfusion [43]. Chang et al. reported that pretreatment with puerarin effectively reduces the cerebral infarct size and neurobehavioral deficits $24 \mathrm{~h}$ after MCAo. The anti-infarct effect of puerarin is, at least partially, because of the inhibition of TNF- $\alpha$ and iNOS expression in the ischemic area [44]. Li et al. explored the effect of osthole, a major active ingredient in Cnidium monnieri (L.) Gusson (She Chuang Zi), on acute cerebral $\mathrm{I} / \mathrm{R}$ injury and reported that pretreatment with osthole markedly reduces the brain infarct volume and ameliorates neurological scores $24 \mathrm{~h}$ after MCAo. The neuroprotective effects of osthole are accompanied by the downregulation of proinflammatory mediators, including TNF- $\alpha$, IL- $1 \beta$, COX-2, and iNOS, expressed in the ischemic cortex [45]. The caffeic acid ester (Caf) fraction from Erigeron breviscapus (Deng Zhan Hua) significantly reduces the cerebral infarct volume and improves neurobehavioral performance at $1 \mathrm{~h}$ of ischemia and $24 \mathrm{~h}$ of reperfusion. The inhibition of iNOS, TNF- $\alpha$, and IL- $1 \beta$ mRNA expression is one of the mechanisms underlying the neuroprotective effects of Caf against cerebral infarction [46]. Pretreatment with arctigenin, an active agent from Arctium lappa (Nu Bang Zi), effectively inhibits microglial activation and subsequently downregulates TNF- $\alpha$ and IL-1 $\beta$ expression in the penumbra region $24 \mathrm{~h}$ after transient MCAo [47]. Lee et al. reported that schisandrin B isolated from Fructus schisandrae (Wu Wei Zi) markedly reduces the cerebral infarct size and neurological deficits $24 \mathrm{~h}$ after transient focal cerebral ischemia. The anti-inflammatory effect of schisandrin $\mathrm{B}$ involves the inhibition of TNF- $\alpha$, IL-1 $\beta$, MMP-2, and MMP-9 expression and suppression of microglial activation in the ischemic area [48]. Posttreatment with asiaticoside, an active compound isolated from Centella asiatica (L.) (Ji Xue Cao), attenuates memory deficits by suppressing iNOS, TNF- $\alpha$, IL- $1 \beta$, and IL-6 expression in the hippocampus $7 \mathrm{~d}$ after transient bilateral common carotid artery occlusion [49]. Chen et al. reported that posttreatment with magnolol, an active ingredient of Magnolia officinalis (Hou $\mathrm{Pu}$ ), ameliorates cerebral infarction partially by dose-dependently inhibiting iNOS, TNF- $\alpha$, IL- $1 \beta$, and IL- 6 expression in the ischemic area $24 \mathrm{~h}$ after transient global ischemia [50]. Posttreatment with danhong, extracted from Radix salviae miltiorrhizae (Dan Shen) and Flos carthami (Hong Hua), exerts beneficial effects in cerebral $\mathrm{I} / \mathrm{R}$ injury, at least partially, through dose-dependent IL- $1 \beta$ and TNF- $\alpha$ downregulation in the ischemia area at $1.5 \mathrm{~h}$ of ischemia and $14 \mathrm{~d}$ of reperfusion [51]. Gastrodin, an active constituent of Gastrodia elata Blume (Tian Ma), exerts an initial anti-inflammatory effect by suppressing TNF- $\alpha$ and IL- $1 \beta$ expression in the ischemic hemispheres $6 \mathrm{~h}$ after cerebral I/R injury [52].

5.5. The Effects and Mechanisms of TCMs on Regulating Anti-Inflammatory Cytokines in In Vivo Models of Cerebral Ischemia. IL-4, IL-10, IL-13, and TGF- $\beta$ reduce microglia/ macrophages-induced proinflammatory cytokines, such as IL-8 [99]. Moreover, IL-4 promotes long-term recovery after ischemic stroke [100]. IL-10 can inhibit IL-1 and TNF- $\alpha$ expression [55] and prevent the downregulation of the antiapoptotic protein Bcl-2 expressed in ischemic brain lesion [101]. IL-4 mRNA generates as early as $1 \mathrm{~h}$, reaches a peak at $3-24 \mathrm{~h}$, and gradually declines $2 \mathrm{~d}$ following ischemic stroke [102]. Pretreatment with danshen, an aqueous extract of the root and rhizome of Salvia miltiorrhiza Bunge (Dan Shen), protects against cerebral I/R injury in association with decreased IL-10 and TNF- $\alpha$ mRNA and protein expression in the ischemic area $24 \mathrm{~h}$ after transient MCAO [53]. Guizhi fuling capsules, composed of Cinnamomum cassia Blume (Gui Zhi), P. lactiflora Pall (Shao Yao), P. suffruticosa Andrews (Mu Dan Pi), P. persica Batsch (Tao Ren), and Poria cocos Wolf (Fu Ling), protect against cerebral infarction through TNF$\alpha$ and IL- $1 \beta$ mRNA and protein downregulation and IL-10 and IL-10 receptor (IL-10R) mRNA and protein upregulation in the ischemia area after $2 \mathrm{~h}$ of ischemia and $24 \mathrm{~h}$ of reperfusion [54]. Zhang et al. also reported that the Gualou Guizhi decoction composed of Trichosanthis radix (Tian Hua Fen), Ramulus cinnamomi (Gui Zhi), P. lactiflora (Shao Yao), Glycyrrhiza (Gan Zao), Zingiber officinale Roscoe (Sheng Jiang), and Fructus jujubae (Da Zao) exerts neuroprotection against cerebral I/R injury through IL-1, TNF- $\alpha$, and NF- $\kappa$ B downregulation and IL-10 upregulation in the ischemic area in the subacute phase (7 d) after transient MCAo [55].

5.6. The Effects and Mechanisms of TCMs on Downregulating Proinflammatory Enzymes in In Vivo Models of Cerebral Ischemia. COX-2 and 5-lipoxygenase (5-LO) are rate-limiting enzymes that convert arachidonic acid to prostaglandins and leukotrienes [57]. In the delayed phase of cerebral ischemia, microglia/macrophages produce 5-LO, which converts arachidonic acid to leukotrienes. Leukotrienes are potent inflammatory mediators that trigger chemotaxis of leukocytes and BBB damage and subsequently cause vasogenic edema, thus exacerbating cerebral ischemia [103]. COX-2 and 5-LO expression is markedly enhanced in the ischemic cortex $24 \mathrm{~h}$ after cerebral I/R injury [57]. Guo et al. explored the anti-infarct effect of paeoniflorin $(\mathrm{PF})$, the principle component of $P$. radix (Shao Yao), in the subacute phase of cerebral I/R injury and reported that $\mathrm{PF}$ protects against cerebral infarction mainly through TNF- $\alpha$, IL- $1 \beta$, iNOS, COX-2, and 5-LO downregulation in the ischemic area $14 \mathrm{~d}$ after reperfusion [56]. Chen et al. reported that pretreatment with PF effectively ameliorates the cerebral infarct volume and neurological deficits $24 \mathrm{~h}$ after reperfusion in a model of pharmacological preconditioning. The neuroprotective effects of $\mathrm{PF}$ against cerebral I/R injury are partially related to the inhibition of COX-2, 5-LO, and iNOS expression in the ischemic lesion [57].

According to the aforementioned studies, proinflammatory mediators, such as TLR4, TNF- $\alpha$, IL- $1 \beta$, IL-6, IL18 , COX-2, and 5-LO, are predominately expressed in the ischemic area $24 \mathrm{~h}$ after MCAo. TCMs effectively ameliorate cerebral I/R injury by downregulating TLR4, TNF- $\alpha$, IL-1 $\beta$, IL-6, iNOS, COX-2, and 5-LO expression and upregulating IL-10 expression in the ischemic area during the acute and subacute phases of cerebral ischemia (Figure 1 and Table 4). 
TABLE 4: TCMs regulate the cytokine release in the inflammatory cascade in ischemic stroke models.

\begin{tabular}{|c|c|c|c|c|}
\hline TCMs & $\begin{array}{c}\text { Isolated from the Chinese } \\
\text { herb (Chinese name) }\end{array}$ & Anti-inflammatory actions & Models & References \\
\hline Puerarin & Ge Gen & $\begin{array}{c}\text { TLR4 } \downarrow \text {, MyD88 } \downarrow \text {, } \\
\text { NF- } \kappa \text { Bp } 65 \downarrow \text {, TNF- } \alpha \downarrow\end{array}$ & $\begin{array}{c}\text { MCAo } \\
1.5 \mathrm{~h} \text { of ischemia followed } \\
\text { by } 24 \mathrm{~h} \text { of reperfusion }\end{array}$ & {$[41]$} \\
\hline Tetramethylpyrazine & Chuan Xiong & $\begin{array}{c}\text { TLR4 } \downarrow, \text { HMGB1 } \downarrow, \text { Nrf2 } \uparrow, \\
\text { HO- } 1 \uparrow \\
\end{array}$ & $\begin{array}{c}\text { Permanent MCAo } \\
3 \mathrm{~d} \text { of ischemia }\end{array}$ & {$[42]$} \\
\hline Notoginseng & San Qi & IL-1 $\beta \downarrow$ & $\begin{array}{c}\text { MCAo } \\
2 \mathrm{~h} \text { of ischemia followed by } \\
22 \mathrm{~h} \text { of reperfusion }\end{array}$ & {$[43]$} \\
\hline Puerarin & Ge Gen & TNF- $\alpha \downarrow$, iNOS $\downarrow$ & $\begin{array}{c}\text { MCAo } \\
1 \mathrm{~h} \text { of ischemia followed by } \\
24 \mathrm{~h} \text { of reperfusion }\end{array}$ & {$[44]$} \\
\hline Osthole & She Chuang Zi & $\begin{array}{c}\text { TNF- } \alpha \downarrow, \text { IL- } 1 \beta \downarrow, \text { COX- } 2 \downarrow \\
\text { iNOS } \downarrow\end{array}$ & $\begin{array}{l}\text { Permanent MCAo } \\
24 \mathrm{~h} \text { of ischemia }\end{array}$ & {$[45]$} \\
\hline Caffeic acid ester & Deng Zhan Hua & $\begin{array}{c}\text { iNOS mRNA } \downarrow \text {, } \\
\text { TNF- } \alpha \text { mRNA } \downarrow \text {, } \\
\text { IL- } 1 \beta \text { mRNA } \downarrow\end{array}$ & $\begin{array}{c}\text { MCAo } \\
1 \mathrm{~h} \text { of ischemia followed by } \\
24 \mathrm{~h} \text { of reperfusion }\end{array}$ & {$[46]$} \\
\hline Arctigenin & $\mathrm{Nu}$ Bang $\mathrm{Zi}$ & $\begin{array}{l}\text { TNF- } \alpha \downarrow, \text { IL- } 1 \beta \downarrow \\
\text { OX- } 42 \downarrow\end{array}$ & $\begin{array}{c}\text { MCAo } \\
2 \mathrm{~h} \text { of ischemia followed by } \\
24 \mathrm{~h} \text { of reperfusion }\end{array}$ & {$[47]$} \\
\hline Schisandrin B & Wu Wei Zi & $\begin{array}{l}\text { TNF- } \alpha \downarrow, \text { IL- } 1 \beta \downarrow, \\
\text { MMP- } 2 \downarrow, \text { MMP-9 } \\
\text { OX-42 }\end{array}$ & $\begin{array}{c}\text { MCAo } \\
2 \mathrm{~h} \text { of ischemia followed by } \\
24 \mathrm{~h} \text { of reperfusion }\end{array}$ & {$[48]$} \\
\hline Asiaticoside & Ji Xue Cao & $\begin{array}{c}\text { iNOS } \downarrow, \text { TNF- } \alpha \downarrow, \text { IL-1 } \beta \downarrow, \\
\text { IL- } 6 \downarrow\end{array}$ & $\begin{array}{c}\text { BCCAo } \\
10 \text { min of ischemia (repeat } 2 \\
\text { times) followed by } 7 \mathrm{~d} \text { of } \\
\text { reperfusion }\end{array}$ & {$[49]$} \\
\hline Magnolol & Hou $\mathrm{Pu}$ & $\begin{array}{l}\text { iNOS } \downarrow \text {, TNF- } \alpha \downarrow \text {, IL-1 } \beta \downarrow \text {, } \\
\quad \text { IL-6 } \downarrow, \text { NF- } \kappa \text { Bp } 65 \downarrow\end{array}$ & $\begin{array}{c}\text { BCCAo } \\
1.5 \mathrm{~h} \text { of ischemia followed } \\
\text { by } 24 \mathrm{~h} \text { of reperfusion }\end{array}$ & {$[50]$} \\
\hline Danhong injection & Dan Shen and Hong Hua & TNF- $\alpha \downarrow$, IL-1 $\beta \downarrow$ & $\begin{array}{c}\text { MCAo } \\
1.5 \mathrm{~h} \text { of ischemia followed } \\
\text { by } 14 \mathrm{~d} \text { of reperfusion }\end{array}$ & {$[51]$} \\
\hline Gastrodin & Tian Ma & TNF- $\alpha \downarrow$, IL-1 $\beta \downarrow$ & $\begin{array}{c}\text { MCAo } \\
1 \mathrm{~h} \text { of ischemia followed by } \\
6 \mathrm{~h} \text { of reperfusion }\end{array}$ & {$[52]$} \\
\hline Danshen & Dan Shen & $\begin{array}{c}\text { IL-10 mRNA } \downarrow \text {, } \\
\text { TNF- } \alpha \text { mRNA } \downarrow \text {, IL-10 } \downarrow \text {, } \\
\text { TNF- } \alpha \downarrow\end{array}$ & $\begin{array}{c}\text { MCAo } \\
1 \mathrm{~h} \text { of ischemia followed by } \\
24 \mathrm{~h} \text { of reperfusion }\end{array}$ & {$[53]$} \\
\hline Guizhi fuling capsules & $\begin{array}{l}\text { Gui Zhi, Shao Yao, Mu } \\
\text { Dan, Tao Ren, Fu Ling }\end{array}$ & $\begin{array}{c}\text { TNF- } \alpha \text { mRNA } \downarrow \text {, } \\
\text { IL-1 } \beta \text { mRNA } \downarrow, \text { TNF- } \alpha \downarrow \text {, } \\
\text { IL-1 } \beta \downarrow, \text { IL-10 mRNA } \uparrow, \\
\text { IL-10R mRNA } \uparrow, \text { IL-10 } \uparrow, \\
\text { IL-10R } \uparrow \\
\end{array}$ & $\begin{array}{c}\text { MCAo } \\
2 \mathrm{~h} \text { of ischemia followed by } \\
24 \mathrm{~h} \text { of reperfusion }\end{array}$ & {$[54]$} \\
\hline Gualou Guizhi decoction & $\begin{array}{c}\text { Tian Hua Fen, Gui Zhi, } \\
\text { Shao Yao, Gan Zao, Sheng } \\
\text { Jiang, Da Zao }\end{array}$ & $\begin{array}{c}\text { TNF- } \alpha \downarrow, \text { IL-1 } \downarrow \\
\text { NF- } \kappa \text { Bp } 65 \downarrow, \text { IL-10个 }\end{array}$ & $\begin{array}{c}\text { MCAo } \\
2 \mathrm{~h} \text { of ischemia followed by } \\
7 \mathrm{~d} \text { of reperfusion }\end{array}$ & {$[55]$} \\
\hline Paeoniflorin & Shao Yao & $\begin{array}{l}\text { TNF- } \alpha \downarrow, \text { IL- } 1 \beta \downarrow, \text { iNOS } \downarrow \text {, } \\
\text { COX- } 2 \downarrow, 5-L O \downarrow\end{array}$ & $\begin{array}{c}\text { MCAo } \\
1.5 \mathrm{~h} \text { of ischemia followed } \\
\text { by } 14 \mathrm{~d} \text { of reperfusion }\end{array}$ & {$[56]$} \\
\hline Paeoniflorin & Shao Yao & COX- $2 \downarrow, 5-\mathrm{LO} \downarrow$, iNOS $\downarrow$ & $\begin{array}{c}\text { MCAo } \\
1.5 \mathrm{~h} \text { of ischemia followed } \\
\text { by } 24 \mathrm{~h} \text { of reperfusion }\end{array}$ & {$[57]$} \\
\hline
\end{tabular}

TLR4, toll-like receptor 4; MyD88, myeloid differentiation primary response gene 88; HMGB1, high mobility group box 1; Nrf2, nuclear factor-erythroid 2related factor 2; HO-1, heme oxygenase-1; iNOS, inducible nitric oxidase synthase; 5-LO, 5-lipoxygenase. 


\section{TCM-Mediated Regulation of Transcription Factor Activation}

6.1. NF- $\kappa B$ Activation during Cerebral Ischemia. NF- $\kappa \mathrm{B}$ is a classic transcription factor and plays a crucial role in the regulation of hundreds of genes involved in cell survival and death [104]. Thus, NF- $\kappa \mathrm{B}$ can be activated via several intracellular signaling pathways associated with host defense, inflammation, and apoptosis [58]. In the brain, $\mathrm{NF}-\kappa \mathrm{B}$ regulates the expression of different sets of genes, such as antiapoptotic, proapoptotic, and proinflammatory genes, thereby playing a dual role in neuronal survival and death [63]. The NF$\kappa \mathrm{B}$ family includes five members, namely, p65 (RelA), RelB, c-Rel, p50/p105 (NF- $\kappa$ B1), and p52/p100 (NF- $\kappa$ B2), which form various homo- and heterodimeric complexes [2]. The most common form of NF- $\kappa \mathrm{B}$ is the p65/p50 heterodimer [6]. Under an unstimulated condition, the inhibitor of NF$\kappa \mathrm{B}$ proteins ( $\mathrm{I} \kappa \mathrm{B} s$ ), including mainly $\mathrm{I} \kappa \mathrm{B} \alpha, \mathrm{I} \kappa \mathrm{B} \beta$, and $\mathrm{I} \kappa \mathrm{B} \varepsilon$, retain inactive $\mathrm{NF}-\kappa \mathrm{B}$ dimmers in the cytosol, whereas in response to various extracellular stimuli, including infection, proinflammatory cytokines, and antigen receptor engagement, the activated $\mathrm{I} \kappa \mathrm{B}$ kinase complexes phosphorylate $\mathrm{I} \kappa \mathrm{B}$ proteins, resulting in their ubiquitination and proteasomal degradation and consequently inducing the release of NF$\kappa \mathrm{B}$ for nuclear translocation and the activation of target gene transcription $[6,105]$. During cerebral ischemia, the activated $\mathrm{NF}-\kappa \mathrm{B}$ dimers are subsequently translocated into the nucleus where they selectively bind to specific DNA sequences called $\kappa \mathrm{B}$ sites; promoter domains present a large number of proinflammatory genes and subsequently cause TNF- $\alpha$, IL$1 \beta$, IL-6, ICAM-1, PGE2, COX-2, and iNOS translation [6, $105,106]$. NF- $\kappa \mathrm{B}$ activators include some proinflammatory cytokines, such as TNF- $\alpha$ and IL- $1 \beta$, whose genes are regulated by NF- $\kappa$ B itself, inducing a positive feedback loop and resulting in the amplification of the inflammatory response and exacerbation of cerebral ischemic insults [107]. Previous studies have indicated that NF- $\kappa \mathrm{B}$ activation occurs as early as $1 \mathrm{~h}$, reaches a peak at $6 \mathrm{~h}$, and sustains for at least $72 \mathrm{~h}$ in the cerebral ischemic area in rats $[62,107]$.

6.2. The Effects and Mechanisms of TCMs on Downregulating $N F-\kappa B$ Activation in In Vivo Models of Cerebral Ischemia. Wogonin, a flavonoid derived from Scutellaria baicalensis Georgi (Huang Qin), exerts neuroprotective effects by inhibiting the inflammatory activation of microglia in an in vitro cell culture model. The anti-inflammatory effects of wogonin are partially attributed to the downregulation of NF- $\kappa \mathrm{B}$-mediated iNOS and TNF- $\alpha$ expression in the ischemic hippocampal CA1 area in transient global cerebral ischemia in rats [58]. Tanshinone IIA (Ts IIA) and IIB, the key compounds of $S$. miltiorrhiza Bunge, effectively reduce the cerebral infarct volume and improve the neurological function $24 \mathrm{~h}$ after transient MCAo [59]. Dong et al. further reported that pretreatment with Ts IIA protects against cerebral infarction partially associated with the reduction of ROS-mediated NF- $\kappa \mathrm{B}$ activation, leading to the inhibition of iNOS expression in the ischemic area $24 \mathrm{~h}$ after permanent MCAo [60]. Silymarin, a bioactive component isolated from Silybum marianum (Shui Fei Ji), provides neuroprotection against cerebral I/R injury by inhibiting oxidative and nitrosative stress in the ischemic area $24 \mathrm{~h}$ after cerebral ischemia. The antioxidative and antinitrosative effects of silymarin are partially attributed to the reduction of NF- $\kappa \mathrm{B}$-mediated iNOS, COX-2, ICAM-1, TNF- $\alpha$, and IL$1 \beta$ expression in the injured tissues [61]. In addition, Guan et al. reported that ruscogenin, a major effective compound isolated from O. japonicus Ker-Gawl, ameliorates cerebral I/R injury through the downregulation of NF- $\kappa \mathrm{B}$ target genes, including ICAM-1, iNOS, COX-2, TNF- $\alpha$, and $I L-1 \beta$, in the ischemic area $24 \mathrm{~h}$ after reperfusion [62]. Hydroxysafflor yellow A, a major active component of C. tinctorius L. (Hong Hua), reduces cerebral infarction by suppressing cytosolic $\mathrm{NF}-\kappa \mathrm{Bp} 65$ translocation to the nucleus and subsequently downregulates NF- $\kappa$ B-mediated TNF- $\alpha$, IL- $1 \beta$, and IL- 6 expression in the ischemic area $24 \mathrm{~h}$ after permanent MCAo [63]. Chern et al. reported that 2-methoxystypandrone (2MS), a major active component of Polygonum cuspidatum (Hu Zhang), attenuates the brain infarct size and improves the neurological function, at least partially, by preventing $\mathrm{I} \kappa \mathrm{B} \alpha$ degradation and a reducing NF- $\kappa \mathrm{B}$-mediated iNOS and COX-2 expression in the peri-infarct cortex $24 \mathrm{~h}$ after transient MCAo. The anti-inflammatory effects of 2-MS can further contribute toward the preserving BBB integrity [64]. Previous studies have indicated that p38 mitogen-activated protein kinase (MAPK), one of the MAPK family members, upregulates $\mathrm{NF}-\kappa \mathrm{B}$ expression (p38 MAPK/NF- $\kappa \mathrm{B}$ signaling) and subsequently causes the transcription of genes encoding proinflammatory cytokines, resulting in the exacerbation of cerebral infarction in the acute phase of transient MCAo [108-110]. In addition, activated p38 MAPK occurs in the ischemic area as early as $2 \mathrm{~h}$ and reaches a peak $24-48 \mathrm{~h}$ after reperfusion [110]. Piperlonguminine from Piper longum (Bi Bo) alkaloids protects against cerebral ischemic injury by inhibiting the activation of p $38 \mathrm{MAPK} / \mathrm{NF}-\kappa \mathrm{B}$ signaling cascade in the ischemic region $24 \mathrm{~h}$ after permanent MCAo [65].

\subsection{The Effects and Mechanisms of TCMs on Upregulating} Peroxisome Proliferator-Activated Receptor Activation in In Vivo Models of Cerebral Ischemia. Peroxisome proliferatoractivated receptors (PPARs) include PPAR $\alpha, \operatorname{PPAR} \gamma$, and $\operatorname{PPAR} \delta / \beta$ isoforms, which are members of the nuclear receptor superfamily and represent ligand-activated transcription factors. PPAR $\gamma$ is predominantly expressed in the central nervous system and binds to peroxisome proliferator response elements to regulate its target gene expression [66]. During cerebral ischemia, PPAR $\gamma$ is detected in the peri-infarct area as early as $4 \mathrm{~h}$ and is sustained for at least $14 \mathrm{~d}$ after ischemia [111]. PPAR $\gamma$ exerts neuroprotective effects against inflammatory mediators to initiate responses by inhibiting the activation of NF- $\kappa \mathrm{B}$ signaling in the ischemic area after focal cerebral ischemia $[66,111]$. Liu et al. reported that pretreatment with curcumin, a natural polyphenolic component of curcuma longa (Jiang Huang), markedly reduces the cerebral infarct volume by activating PPAR $\gamma$ signaling in the ischemic cortex $24 \mathrm{~h}$ after reperfusion. The effects of curcumin on the regulation of PPAR $\gamma$ signaling further contribute to the downregulation of NF- $\kappa$ Bp65-mediated TNF- $\alpha$, IL- $1 \beta$, 
iNOS, PGE2, and COX-2 expression [66]. Another study revealed that pretreatment with icariin, a natural flavonoid compound extracted from Epimedium brevicornum maxim (Yin Yang Huo), protects against cerebral I/R injury by activating PPAR $\alpha$ and PPAR $\gamma$ and subsequently suppressing NF- $\kappa$ Bp 65 -mediated IL- $1 \beta$ expression in the ischemic cortex at $2 \mathrm{~h}$ of ischemia and $24 \mathrm{~h}$ of reperfusion [67].

6.4. The Effects and Mechanisms of TCMs on Regulating Signal Transducer and Activator of Transcription Activation in In Vivo Models of Cerebral Ischemia. Signal transducer and activator of transcription (STAT) proteins are a family of transcription factors comprising seven members, namely, STAT1, STAT2, STAT3, STAT4, STAT5a, STAT5b, and STAT6 [112]. Some controversy exists on whether STAT signaling is neuroprotective or neurotoxic in cerebral ischemic injury [113]. Growing evidence has revealed that cytokines induce the activation of the receptor-associated Janus kinases (JAKs), including JAK1, JAK2, JAK3, and tyrosine kinase 2, which consequently activate STAT proteins; the activated STAT proteins undergo dimerization and translocation to the nucleus, thereby regulating the expression of proapoptotic and proinflammatory genes $[114,115]$. Among STAT protein isoforms, STAT3 is the most-conserved isoform [68]. In the transient cerebral ischemic rat model, STAT3 is activated as early as $30 \mathrm{~min}$ and sustained $24 \mathrm{~h}$ after reperfusion, and activated STAT3 triggers cerebral I/R injury by amplifying inflammatory responses [116]. However, other studies have reported that activated STAT3 signaling provides neuroprotection by upregulating Bcl-2 and vascular endothelial growth factor expression in the peri-infarct area after transient cerebral ischemia [113, 117]. Kaempferol-3-O-rutinoside (KRS) and kaempferol-3-O-glucoside (KGS) are also the active components of C. tinctorius L. Both KRS and KGS markedly reduce the cerebral infarct volume at least partially associated with the inhibition of STAT3 and NF- $\kappa$ Bp 65 activation, and subsequently, proinflammatory mediators (TNF- $\alpha$, IL- $1 \beta$, iNOS, MMP-9, and ICAM-1) production in the cortical penumbra $24 \mathrm{~h}$ after transient MCAo [68]. Astragaloside IV [the active component of Astragalus (Huang Qi)] combined with Ginsenoside Rg1, Ginsenoside Rb1, and Notoginsenoside R1 (the active components of $P$. notoginseng) effectively restores cell survival partially related to the inhibition of JAK1/STAT1 and $\mathrm{NF}-\kappa \mathrm{B}$ signaling and consequently suppresses TNF- $\alpha$, IL- $1 \beta$, and ICAM-1 mRNA expression in the ischemic area $24 \mathrm{~h}$ after transient global cerebral ischemia [69]. By contrast, Li et al. reported that curcumin reduces cerebral infarction and attenuates neurological deficits by activating JAK2/STAT3 signaling and downregulating IL- $1 \beta$ and IL- 8 in the injured region after $24 \mathrm{~h}$ of reperfusion [70].

6.5. The Effects and Mechanisms of TCMs on Regulating Nuclear Factor-Erythroid 2-Related Factor 2/Heme Oxygenase-1 and c-Jun N-Terminal Kinase/c-Jun/Activating Protein1 Signaling in an In Vivo Model of Cerebral Ischemia. Nuclear factor-erythroid 2-related factor 2 (Nrf2), a potent cytoprotective transcription factor, induces the expression of genes encoding antioxidant and anti-inflammatory proteins
[118]. Under stress, Nrf2 dissociates from its cytoplasmic inhibitory protein Kelch-like ECH-associated protein 1 and translocates into the nucleus, where it binds to an antioxidant response element and regulates target genes, including heme oxygenase-1 (HO-1). The $\mathrm{Nrf} 2 / \mathrm{HO}-1$ signaling pathway attenuates inflammatory responses in cerebral ischemia [71]. During transient focal cerebral ischemia, Nrf2 and HO1 occur in the ischemic cortex as early as $6 \mathrm{~h}$, up to a maximum $48 \mathrm{~h}$ and decline $72 \mathrm{~h}$ after cerebral I/R [119]. The activation of c-Jun N-terminal kinase (JNK), one of the MAPK family members, signaling plays a central role in ischemia-induced neuroinflammation. When stimulated, activated JNK translocates into the nucleus and phosphorylates $\mathrm{c}$-Jun, the major component of activating protein(AP-) 1, which comprises c-Jun and c-Fos proteins, leading to the expression of target genes encoding proinflammatory mediators. JNK/AP-1 signaling amplifies the inflammatory response during cerebral ischemia [71]. JNK/c-Jun/AP-1 signaling factors are predominantly expressed in the ischemic area $2 \mathrm{~h}$ after cerebral ischemia [120]. Kao et al. reported that TMP effectively reduces cerebral infarction by inhibiting microglia/macrophages activation in the ischemic cortex $72 \mathrm{~h}$ after permanent MCAo. The anti-inflammatory effects of TMP can be further attributed to the upregulation of Nrf2/HO-1 signaling and downregulation of JNK/c-Jun/AP-1 signaling in the ischemic cortex [71].

According to the aforementioned studies, NF- $\kappa \mathrm{B}$ and JNK/AP-1 signaling induced in the ischemic brain may amplify inflammatory responses, whereas PPARs and Nrf2/HO-1 signaling are considered to prevent postischemic inflammation and yield potent effects against cerebral ischemic injury. JAK/STAT signaling plays a dual role in the regulation of proinflammatory mediators depending on the experimental models of brain ischemia. TCMs protect against cerebral ischemic injury by inhibiting deleterious transcription factors (NF- $\kappa \mathrm{B}$, JAK/STAT, and JNK/AP-1), activating neuroprotective transcription factors (PPARs and $\mathrm{Nrf} / \mathrm{HO}-1$ ) and consequently regulating the expression of transcription factor-mediated proinflammatory genes (TNF- $\alpha$, IL-1 $\beta$, IL-6, IL-8, iNOS, COX-2, PGE2, MMP-9, and ICAM-1) in the ischemic area in the early stage (24-72 h) of cerebral ischemia (Figure 2 and Table 5).

\section{Conclusions}

After the onset of cerebral ischemia, resident microglia are rapidly activated (within a few minutes) and subsequently produce large amounts of cytokines, chemokines, and ROS, thus causing the initial ischemic injury. TCMs can exert neuroprotective effects against the initial ischemic injury by rapidly downregulating ischemia-induced microglial activation and microglia-mediated proinflammatory cytokine production in the ischemic region. The microglial production of proinflammatory mediators subsequently increase adhesion molecule expression, facilitate leukocyte-endothelial cell interactions, and activated leukocytes that penetrate the endothelial cell barrier into the brain parenchyma (as early as $4 \mathrm{~h}$ after the ischemic onset). The infiltrating leukocytes further release inflammatory mediators in the 


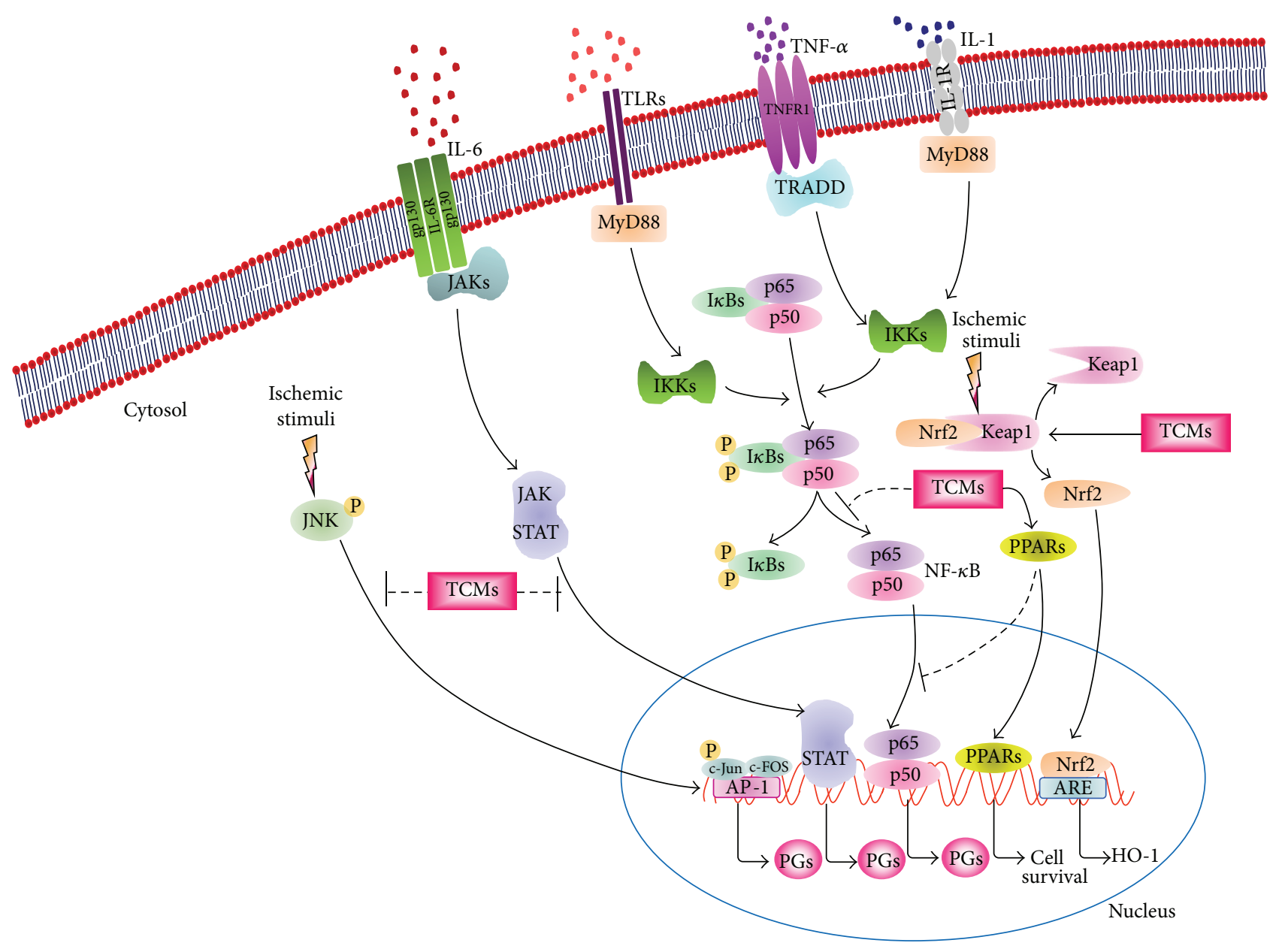

FIGURE 2: Schematic representation of the anti-inflammatory effects of traditional Chinese medicines through the regulation of transcription factors in the inflammatory cascade after cerebral ischemia. JAKs, Janus kinases; MyD88, myeloid differentiation primary response gene 88; TRADD, tumor necrosis factor receptor type 1-associated death domain; I $\kappa$ Bs, inhibitor of NF- $\kappa$ B proteins; IKKs, I $\kappa$ B kinases; Nrf2, nuclear factor-erythroid 2-related factor 2; Keap1, Kelch-like ECH-associated protein 1; PPARs, peroxisome proliferator-activated receptors; STAT, signal transducer and activator of transcription; JNK, c-Jun N-terminal kinase; AP-1, activating protein-1; ARE, antioxidant response element; HO-1, heme oxygenase-1; PGs, proinflammatory genes. Thick solid lines with arrowheads indicate activation, and thin dotted lines indicate inhibition.

ischemic lesion, thus exacerbating ischemic injury. TCMs can effectively attenuate leukocyte infiltration by inhibiting ICAM-1 and activated leukocyte-induced cytokine expression in the ischemic region in the early phase of cerebral ischemia. Meanwhile, infiltrated leukocytes and activated microglia secrete MMPs, which cause the disruption of BBB integrity, worsening cerebral infarction. TCMs effectively inhibit MMPs expression and stabilize BBB integrity to ameliorate cerebral infarction. Increased TLRs stimulation in microglia/macrophages (activated microglia and recruited leukocytes) by the activation of intercellular signaling pathways robustly secretes various proinflammatory mediators (cytokines and enzymes) in the ischemic region 6-24h after ischemia. TCMs can timely rescue the injured neurons by downregulating proinflammatory receptors (TLRs), cytokines, and enzymes and upregulating anti-inflammatory cytokine expression in the ischemic lesion. The proinflammatory transcription factors are subsequently activated by the secreted cytokines, whose genes are regulated by these transcription factors themselves, thus inducing a positive feedback loop, in which the inflammatory response is amplified and secondary brain injury is exacerbated $24-72 \mathrm{~h}$ after cerebral ischemia. TCMs protect against inflammatory response-induced secondary brain injury by inhibiting deleterious transcription factors, activating neuroprotective transcription factors, and consequently regulating the expression of transcription factor-mediated proinflammatory genes in the ischemic area. Therefore, TCMs provide promising antiinflammatory therapeutic strategies in the acute phase of cerebral ischemia. However, further studies are needed to elucidate the precise mechanisms of TCMs against inflammatory responses in the ischemic cascade after stroke.

\section{Competing Interests}

The authors have declared that no competing interests exist. 
TABLE 5: TCMs regulate transcription factors in the inflammatory cascade in ischemic stroke models.

\begin{tabular}{|c|c|c|c|c|}
\hline TCMs & $\begin{array}{c}\text { Isolated from the Chinese } \\
\text { herb (Chinese name) }\end{array}$ & Anti-inflammatory actions & Models & References \\
\hline Wogonin & Huang Qin & $\begin{array}{l}\text { NF- } \kappa \text { Bp } 65 \downarrow \text {, iNOS } \downarrow \text {, } \\
\text { TNF- } \alpha \downarrow\end{array}$ & $\begin{array}{c}4-\mathrm{VO} \\
10 \mathrm{~min} \text { of ischemia followed by } \\
7 \mathrm{~d} \text { of reperfusion }\end{array}$ & {$[58]$} \\
\hline Tanshinone IIA & Dan Shen & NF- $\kappa$ Bp65 $\downarrow$, iNOS $\downarrow$ & $\begin{array}{c}\text { MCAo } \\
2 \mathrm{~h} \text { of ischemia followed by } 24 \mathrm{~h} \\
\text { of reperfusion } \\
\text { Permanent MCAo } \\
24 \mathrm{~h} \text { of ischemia }\end{array}$ & {$[59,60]$} \\
\hline Silymarin & Shui Fei Ji & $\begin{array}{c}\text { NF- } \kappa \text { Bp } 65 \downarrow \text {, iNOS } \downarrow \text {, } \\
\text { COX- } 2 \downarrow, \text { ICAM- } 1 \downarrow, \text { IL- } 1 \beta \downarrow, \\
\text { MPO } \downarrow\end{array}$ & $\begin{array}{c}\text { MCAo } \\
1 \mathrm{~h} \text { of ischemia followed by } 24 \mathrm{~h} \\
\text { of reperfusion }\end{array}$ & {$[61]$} \\
\hline Ruscogenin & Mai Men Dong & $\begin{array}{c}\text { NF- } \kappa \text { Bp } 65 \downarrow, \text { ICAM- } 1 \downarrow \text {, } \\
\text { iNOS } \downarrow, \text { COX- } 2 \downarrow, \text { TNF- } \alpha \downarrow, \\
\text { IL- } 1 \beta \downarrow\end{array}$ & $\begin{array}{l}\text { MCAo } \\
1 \mathrm{~h} \text { of ischemia followed by } 24 \mathrm{~h} \\
\text { of reperfusion }\end{array}$ & {$[62]$} \\
\hline Hydroxysafflor yellow A & Hong Hua & $\begin{array}{c}\text { NF- } \kappa \text { Bp } 65 \downarrow, \text { TNF- } \alpha \downarrow \text {, } \\
\text { IL-1 } \beta \downarrow, \text { IL- } 6 \downarrow\end{array}$ & $\begin{array}{c}\text { Permanent MCAo } \\
24 \mathrm{~h} \text { of ischemia }\end{array}$ & {$[63]$} \\
\hline 2-Methoxystypandrone & Hu Zhang & $\begin{array}{c}\mathrm{NF}-\kappa \mathrm{Bp} 65 \downarrow, \mathrm{I} \kappa \mathrm{B} \alpha \uparrow, \mathrm{iNOS} \downarrow \\
\mathrm{COX}-2 \downarrow\end{array}$ & $\begin{array}{c}\text { MCAo } \\
40 \text { min of ischemia followed by } \\
24 \mathrm{~h} \text { of reperfusion }\end{array}$ & {$[64]$} \\
\hline Piperlonguminine & Bi Bo & NF- $\kappa$ Bp $65 \downarrow$, p-p38 MAPK $\downarrow$ & $\begin{array}{c}\text { Permanent MCAo } \\
24 \mathrm{~h} \text { of ischemia }\end{array}$ & {$[65]$} \\
\hline Curcumin & Jiang Huang & $\begin{array}{c}\text { PPAR } \gamma \uparrow, \text { NF- } \kappa \text { Bp } 65 \downarrow \text {, } \\
\text { I } \kappa \mathrm{B} \alpha \uparrow, \text { TNF- } \alpha \downarrow \text {, IL- } 1 \beta \downarrow \text {, } \\
\text { iNOS } \downarrow, \text { PGE } 2 \downarrow, \text { COX- } 2 \downarrow\end{array}$ & $\begin{array}{c}\text { MCAo } \\
2 \mathrm{~h} \text { of ischemia followed by } 24 \mathrm{~h} \\
\text { of reperfusion }\end{array}$ & {$[66]$} \\
\hline Icariin & Yin Yang Huo & $\begin{array}{l}\text { PPAR } \alpha \uparrow, \text { PPAR } \gamma \uparrow, \\
\text { NF- } \kappa \text { Bp } 65 \downarrow, \text { IL- } 1 \beta \downarrow\end{array}$ & $\begin{array}{c}\text { MCAo } \\
2 \mathrm{~h} \text { of ischemia followed by } 24 \mathrm{~h} \\
\text { of reperfusion }\end{array}$ & {$[67]$} \\
\hline $\begin{array}{l}\text { Kaempferol-3-O-rutinoside } \\
\text { and } \\
\text { kaempferol-3-O-glucoside }\end{array}$ & Hong Hua & $\begin{array}{c}\text { STAT3 } \downarrow, \text { NF- } \kappa \text { Bp } 65 \downarrow \\
\text { TNF- } \alpha \downarrow \text {, IL- } 1 \beta \downarrow \text {, iNOS } \downarrow \text {, } \\
\text { MMP-9 } \downarrow, \text { ICAM- } 1 \downarrow\end{array}$ & $\begin{array}{c}\text { MCAo } \\
2 \mathrm{~h} \text { of ischemia followed by } 24 \mathrm{~h} \\
\text { of reperfusion }\end{array}$ & {$[68]$} \\
\hline $\begin{array}{l}\text { Astragaloside IV, ginsenoside } \\
\text { Rg1, ginsenoside Rb1, } \\
\text { notoginsenoside R1 }\end{array}$ & Huang Qi and San Qi & $\begin{array}{c}\text { JAK1 } \downarrow, \text { STAT1 } \downarrow \text {, } \\
\text { NF- } \kappa \text { Bp } 65 \downarrow, \mathrm{p}-\mathrm{I} \kappa \mathrm{B} \alpha \downarrow \\
\text { TNF- } \alpha \text { mRNA } \downarrow \text {, } \\
\text { IL-1 } \beta \text { mRNA } \downarrow \text {, ICAM-1 } \\
\text { mRNA } \downarrow\end{array}$ & $\begin{array}{c}\text { BCCAo } \\
20 \text { min of ischemia followed by } \\
24 \mathrm{~h} \text { of reperfusion }\end{array}$ & [69] \\
\hline Curcumin & Jiang Huang & $\begin{array}{l}\text { JAK2 } \uparrow, \text { STAT3 } \uparrow, \text { IL- } 1 \beta \downarrow, \\
\text { IL- } 8 \downarrow\end{array}$ & $\begin{array}{l}\text { MCAo } \\
\begin{array}{l}1.5 \mathrm{~h} \text { of ischemia followed by } 24 \mathrm{~h} \\
\text { of reperfusion }\end{array}\end{array}$ & {$[70]$} \\
\hline Tetramethylpyrazine & Chuan Xiong & $\begin{array}{c}\text { Nrf2 } 2, \mathrm{HO}-1 \uparrow, \mathrm{MPO} \downarrow \\
\text { p-c-Jun } \downarrow, \text { p-JNK } \downarrow, \text { AP- } 1 \downarrow\end{array}$ & $\begin{array}{l}\text { Permanent MCAo } \\
72 \mathrm{~h} \text { of ischemia }\end{array}$ & {$[71]$} \\
\hline
\end{tabular}

4-VO, 4-vessel occlusion; I $\kappa \mathrm{B} \alpha$, inhibitor of NF- $\kappa \mathrm{B}$ protein $\alpha$; PPAR $\gamma$, peroxisome proliferator-activated receptor $\gamma$; STAT3, signal transducer and activator of transcription 3; JAK1, Janus kinase 1; AP-1, activating protein-1.

\section{Acknowledgments}

This study was supported by grants from China Medical University Hospital (DMR-105-007), Taichung, Taiwan.

\section{References}

[1] A. Siniscalchi, L. Gallelli, G. Malferrari et al., "Cerebral stroke injury: the role of cytokines and brain inflammation," Journal of Basic and Clinical Physiology and Pharmacology, vol. 25, no. 2, pp. 131-137, 2014.

[2] R. Jin, L. Liu, S. Zhang, A. Nanda, and G. Li, "Role of inflammation and its mediators in acute ischemic stroke," Journal of
Cardiovascular Translational Research, vol. 6, no. 5, pp. 834-851, 2013.

[3] R. Jin, G. Yang, and G. Li, "Inflammatory mechanisms in ischemic stroke: role of inflammatory cells," Journal of Leukocyte Biology, vol. 87, no. 5, pp. 779-789, 2010.

[4] R.-D. Cheng, J.-J. Ren, Y.-Y. Zhang, and X.-M. Ye, "P2X4 receptors expressed on microglial cells in post-ischemic inflammation of brain ischemic injury," Neurochemistry International, vol. 67, no. 1, pp. 9-13, 2014.

[5] M. K. Tobin, J. A. Bonds, R. D. Minshall, D. A. Pelligrino, F. D. Testai, and O. Lazarov, "Neurogenesis and inflammation after ischemic stroke: what is known and where we go from here," 
Journal of Cerebral Blood Flow and Metabolism, vol. 34, no. 10, pp. 1573-1584, 2014.

[6] J. Y. Kim, M. Kawabori, and M. A. Yenari, "Innate inflammatory responses in stroke: mechanisms and potential therapeutic targets," Current Medicinal Chemistry, vol. 21, no. 18, pp. 20762097, 2014.

[7] S. E. Lakhan, A. Kirchgessner, and M. Hofer, "Inflammatory mechanisms in ischemic stroke: therapeutic approaches," Journal of Translational Medicine, vol. 7, article 97, 2009.

[8] E.-Y. Cho, S.-J. Lee, K.-W. Nam et al., "Amelioration of oxygen and glucose deprivation-induced neuronal death by chloroform fraction of bay leaves (Laurus nobilis)," Bioscience, Biotechnology and Biochemistry, vol. 74, no. 10, pp. 2029-2035, 2010.

[9] A. Simats, T. García-Berrocoso, and J. Montaner, "Neuroinflammatory biomarkers: from stroke diagnosis and prognosis to therapy," Biochimica et Biophysica Acta-Molecular Basis of Disease, vol. 1862, no. 3, pp. 411-424, 2016.

[10] J. Galea and D. Brough, "The role of inflammation and interleukin-1 in acute cerebrovascular disease," Journal of Inflammation Research, vol. 6, no. 1, pp. 121-128, 2013.

[11] V. L. Feigin, "Herbal medicine in stroke: does it have a future?" Stroke, vol. 38, no. 6, pp. 1734-1736, 2007.

[12] Z. Liu, P. Li, D. Zhao, H. Tang, and J. Guo, "Anti-inflammation effects of cordyceps sinensis mycelium in focal cerebral ischemic injury rats," Inflammation, vol. 34, no. 6, pp. 639-644, 2011.

[13] K. Sun, J. Fan, and J. Han, "Ameliorating effects of traditional Chinese medicine preparation, Chinese materia medica and active compounds on ischemia/reperfusion-induced cerebral microcirculatory disturbances and neuron damage," Acta Pharmaceutica Sinica B, vol. 5, no. 1, pp. 8-24, 2015.

[14] S. Rivest, "Regulation of innate immune responses in the brain," Nature Reviews Immunology, vol. 9, no. 6, pp. 429-439, 2009.

[15] H. W. Morrison and J. A. Filosa, "A quantitative spatiotemporal analysis of microglia morphology during ischemic stroke and reperfusion," Journal of Neuroinflammation, vol. 10, article 4, 2013.

[16] T. Shichita, M. Ito, and A. Yoshimura, "Post-ischemic inflammation regulates neural damage and protection," Frontiers in Cellular Neuroscience, vol. 8, article 319, 2014.

[17] Q. Zhao, X. Xie, Y. Fan et al., "Phenotypic dysregulation of microglial activation in young offspring rats with maternal sleep deprivation-induced cognitive impairment," Scientific Reports, vol. 5, article 9513, 2015.

[18] E. J. Walker and G. A. Rosenberg, "TIMP-3 and MMP-3 contribute to delayed inflammation and hippocampal neuronal death following global ischemia," Experimental Neurology, vol. 216, no. 1, pp. 122-131, 2009.

[19] Y. Lee, S.-R. Lee, S. S. Choi, H.-G. Yeo, K.-T. Chang, and H. J. Lee, "Therapeutically targeting neuroinflammation and microglia after acute ischemic stroke," BioMed Research International, vol. 2014, Article ID 297241, 9 pages, 2014.

[20] C.-L. Hsieh, C.-Y. Cheng, T.-H. Tsai et al., "Paeonol reduced cerebral infarction involving the superoxide anion and microglia activation in ischemia-reperfusion injured rats," Journal of Ethnopharmacology, vol. 106, no. 2, pp. 208-215, 2006.

[21] S.-L. Liao, T.-K. Kao, W.-Y. Chen et al., "Tetramethylpyrazine reduces ischemic brain injury in rats," Neuroscience Letters, vol. 372, no. 1-2, pp. 40-45, 2004.
[22] T.-K. Kao, Y.-C. Ou, J.-S. Kuo et al., "Neuroprotection by tetramethylpyrazine against ischemic brain injury in rats," Neurochemistry International, vol. 48, no. 3, pp. 166-176, 2006.

[23] S. J. Chan, W. S. F. Wong, P. T. H. Wong, and J.-S. Bian, "Neuroprotective effects of andrographolide in a rat model of permanent cerebral ischaemia," British Journal of Pharmacology, vol. 161, no. 3, pp. 668-679, 2010.

[24] C.-J. Lao, J.-G. Lin, J.-S. Kuo et al., "Microglia, apoptosis and interleukin- $1 \beta$ expression in the effect of Sophora Japonica L. on cerebral infarct induced by ischemia-reperfusion in rats," American Journal of Chinese Medicine, vol. 33, no. 3, pp. 425438, 2005.

[25] D. W. Lim, C. Lee, I.-H. Kim, and Y. T. Kim, "Anti-inflammatory effects of total isoflavones from Pueraria lobata on cerebral ischemia in rats," Molecules, vol. 18, no. 9, pp. 10404-10412, 2013.

[26] A. C. C. da Fonseca, D. Matias, C. Garcia et al., "The impact of microglial activation on blood-brain barrier in brain diseases," Frontiers in Cellular Neuroscience, vol. 8, article 362, 2014.

[27] G. Trendelenburg, "Molecular regulation of cell fate in cerebral ischemia: role of the inflammasome and connected pathways," Journal of Cerebral Blood Flow \& Metabolism, vol. 34, no. 12, pp. 1857-1867, 2014.

[28] G. Yilmaz and D. N. Granger, "Leukocyte recruitment and ischemic brain injury," NeuroMolecular Medicine, vol. 12, no. 2, pp. 193-204, 2010.

[29] J. Monteseirín, E. Llamas, H. Sánchez-Monteseirín et al., "IgEmediated downregulation of L-selectin (CD62L) on lymphocytes from asthmatic patients," Allergy, vol. 56, no. 2, pp. 164168, 2001.

[30] B. M. Famakin, "The immune response to acute focal cerebral ischemia and associated post-stroke immunodepression: a focused review," Aging and Disease, vol. 5, no. 5, pp. 307-326, 2014.

[31] J.-S. Lu, J.-X. Liu, W.-Y. Zhang, S.-W. Liang, D. Wang, and J. Fang, "Preventive effects of Emodin on cerebral ischemia injury and expression of the inflammatory factors in rats with cerebral ischemia," Zhongguo Zhong Yao Za Zhi, vol. 30, no. 24, pp. 19391943, 2005

[32] C.-Y. Cheng, T.-Y. Ho, E.-J. Lee, S.-Y. Su, N.-Y. Tang, and C.-L. Hsieh, "Ferulic acid reduces cerebral infarct through its antioxidative and anti-inflammatory effects following transient focal cerebral ischemia in rats," The American Journal of Chinese Medicine, vol. 36, no. 6, pp. 1105-1119, 2008.

[33] C.-Y. Cheng, S.-Y. Su, N.-Y. Tang, T.-Y. Ho, S.-Y. Chiang, and C.L. Hsieh, "Ferulic acid provides neuroprotection against oxidative stress-related apoptosis after cerebral ischemia/reperfusion injury by inhibiting ICAM-1 mRNA expression in rats," Brain Research, vol. 1209, pp. 136-150, 2008.

[34] H.-W. Wang, K.-T. Liou, Y.-H. Wang et al., "Deciphering the neuroprotective mechanisms of $\mathrm{Bu}$-yang Huan-wu decoction by an integrative neurofunctional and genomic approach in ischemic stroke mice," Journal of Ethnopharmacology, vol. 138, no. 1, pp. 22-33, 2011.

[35] M. S. Miao, X. X. Zhang, M. Bai, and L. N. Wang, "Persimmon leaf flavonoid promotes brain ischemic tolerance," Neural Regeneration Research, vol. 8, no. 28, pp. 2625-2632, 2013.

[36] Z. Lin, D. Zhu, Y. Yan, and B. Yu, "Herbal formula FBD extracts prevented brain injury and inflammation induced by cerebral ischemia-reperfusion," Journal of Ethnopharmacology, vol. 118, no. 1, pp. 140-147, 2008.

[37] Q.-X. Kong, Z.-Y. Wu, X. Chu, R.-Q. Liang, M. Xia, and L. $\mathrm{Li}$, "Study on the anti-cerebral ischemia effect of borneol and 
its mechanism," African Journal of Traditional, Complementary, and Alternative Medicines, vol. 11, no. 1, pp. 161-164, 2014.

[38] M. Lin, W. Sun, W. Gong, Z. Zhou, Y. Ding, and Q. Hou, "Methylophiopogonanone a protects against cerebral ischemia/reperfusion injury and attenuates blood-brain barrier disruption," PLoS ONE, vol. 10, no. 4, Article ID e0124558, 2015.

[39] F. Tan, W. Fu, N. Cheng, D. I. Meng, and Y. Gu, "Ligustrazine reduces blood-brain barrier permeability in a rat model of focal cerebral ischemia and reperfusion," Experimental and Therapeutic Medicine, vol. 9, no. 5, pp. 1757-1762, 2015.

[40] X.-W. Mao, C.-S. Pan, P. Huang et al., "Levotetrahydropalmatine attenuates mouse blood-brain barrier injury induced by focal cerebral ischemia and reperfusion: involvement of Src kinase," Scientific Reports, vol. 5, Article ID 11155, 2015.

[41] F. Zhou, L. Wang, P. P. Liu et al., "Puerarin protects brain tissue against cerebral ischemia/reperfusion injury by inhibiting the inflammatory response," Neural Regeneration Research, vol. 9, no. 23, pp. 2074-2080, 2014.

[42] C.-Y. Chang, T.-K. Kao, W.-Y. Chen et al., “Tetramethylpyrazine inhibits neutrophil activation following permanent cerebral ischemia in rats," Biochemical and Biophysical Research Communications, vol. 463, no. 3, pp. 421-427, 2015.

[43] Y. H. Tang, S. P. Zhang, Y. Liang, and C. Q. Deng, "Effects of Panax notoginseng saponins on mRNA expressions of interleukin-1 $\beta$, its correlative factors and cysteinyl-aspartate specific protease after cerebral ischemia-reperfusion in rats," Zhong Xi Yi Jie He Xue Bao, vol. 5, no. 3, pp. 328-332, 2007.

[44] Y. Chang, C.-Y. Hsieh, Z.-A. Peng et al., "Neuroprotective mechanisms of puerarin in middle cerebral artery occlusioninduced brain infarction in rats," Journal of Biomedical Science, vol. 16, article 9, 2009.

[45] F. Li, Q. Gong, L. Wang, and J. Shi, "Osthole attenuates focal inflammatory reaction following permanent middle cerebral artery occlusion in rats," Biological and Pharmaceutical Bulletin, vol. 35, no. 10, pp. 1686-1690, 2012.

[46] S.-X. Wang, H. Guo, L.-M. Hu et al., "Caffeic acid ester fraction from erigeron breviscapus inhibits microglial activation and provides neuroprotection," Chinese Journal of Integrative Medicine, vol. 18, no. 6, pp. 437-444, 2012.

[47] T. Fan, W. L. Jiang, J. Zhu, and Y. Feng Zhang, "Arctigenin protects focal cerebral ischemia-reperfusion rats through inhibiting neuroinflammation," Biological and Pharmaceutical Bulletin, vol. 35, no. 11, pp. 2004-2009, 2012.

[48] T. H. Lee, C. H. Jung, and D.-H. Lee, "Neuroprotective effects of Schisandrin B against transient focal cerebral ischemia in Sprague-Dawley rats," Food and Chemical Toxicology, vol. 50, no. 12, pp. 4239-4245, 2012.

[49] S. Chen, Z.-J. Yin, C. Jiang et al., "Asiaticoside attenuates memory impairment induced by transient cerebral ischemiareperfusion in mice through anti-inflammatory mechanism," Pharmacology Biochemistry and Behavior, vol. 122, pp. 7-15, 2014.

[50] J.-H. Chen, H.-C. Kuo, K.-F. Lee, and T.-H. Tsai, "Magnolol protects neurons against ischemia injury via the downregulation of p38/MAPK, CHOP and nitrotyrosine," Toxicology and Applied Pharmacology, vol. 279, no. 3, pp. 294-302, 2014.

[51] Z. Wang, F. Song, J. Li et al., "PET demonstrates functional recovery after treatment by danhong injection in a rat model of cerebral ischemic-reperfusion injury," Evidence-Based Complementary and Alternative Medicine, vol. 2014, Article ID 430757, 9 pages, 2014.
[52] Z. Peng, S. Wang, G. Chen et al., "Gastrodin alleviates cerebral ischemic damage in mice by improving anti-oxidant and antiinflammation activities and inhibiting apoptosis pathway," Neurochemical Research, vol. 40, no. 4, pp. 661-673, 2015.

[53] X.-Y. Liang, H.-N. Li, X.-Y. Yang, W.-Y. Zhou, J.-G. Niu, and B.-D. Chen, "Effect of Danshen aqueous extract on serum hsCRP, IL-8, IL-10, TNF- $\alpha$ levels, and IL-10 mRNA, TNF- $\alpha$ mRNA expression levels, cerebral TGF- $\beta 1$ positive expression level and its neuroprotective mechanisms in CIR rats," Molecular Biology Reports, vol. 40, no. 4, pp. 3419-3427, 2013.

[54] T.-J. Li, Y. Qiu, J.-Q. Mao, P.-Y. Yang, Y.-C. Rui, and W.S. Chen, "Protective effects of Guizhi-Fuling-capsules on rat brain ischemia/reperfusion injury," Journal of Pharmacological Sciences, vol. 105, no. 1, pp. 34-40, 2007.

[55] Y. Zhang, S. Zhang, H. Li et al., "Ameliorative effects of Gualou Guizhi decoction on inflammation in focal cerebral ischemicreperfusion injury," Molecular Medicine Reports, vol. 12, no. 1, pp. 988-994, 2015.

[56] R.-B. Guo, G.-F. Wang, A.-P. Zhao, J. Gu, X.-L. Sun, and G. Hu, "Paeoniflorin protects against ischemia-induced brain damages in rats via inhibiting MAPKs/NF- $\kappa$ B-mediated inflammatory responses," PLoS ONE, vol. 7, no. 11, Article ID e49701, 2012.

[57] D.-M. Chen, L. Xiao, X. Cai, R. Zeng, and X.-Z. Zhu, "Involvement of multitargets in paeoniflorin-induced preconditioning," Journal of Pharmacology and Experimental Therapeutics, vol. 319, no. 1, pp. 165-180, 2006.

[58] H. Lee, Y. O. Kim, H. Kim et al., "Flavonoid wogonin from medicinal herb is neuroprotective by inhibiting inflammatory activation of microglia," The FASEB Journal, vol. 17, no. 13, pp. 1943-1944, 2003.

[59] B. Y. H. Lam, A. C. Y. Lo, X. Sun, H. W. Luo, S. K. Chung, and N. J. Sucher, "Neuroprotective effects of tanshinones in transient focal cerebral ischemia in mice," Phytomedicine, vol. 10, no. 4, pp. 286-291, 2003.

[60] K. Dong, W. Xu, J. Yang, H. Qiao, and L. Wu, "Neuroprotective effects of Tanshinone IIA on permanent focal cerebral ischemia in mice," Phytotherapy Research, vol. 23, no. 5, pp. 608-613, 2009.

[61] Y.-C. Hou, K.-T. Liou, C.-M. Chern et al., "Preventive effect of silymarin in cerebral ischemia-reperfusion-induced brain injury in rats possibly through impairing NF- $\kappa$ B and STAT-1 activation," Phytomedicine, vol. 17, no. 12, pp. 963-973, 2010.

[62] T. Guan, Q. Liu, Y. Qian et al., "Ruscogenin reduces cerebral ischemic injury via NF- $\kappa \mathrm{B}$-mediated inflammatory pathway in the mouse model of experimental stroke," European Journal of Pharmacology, vol. 714, no. 1-3, pp. 303-311, 2013.

[63] Y. Liu, Z. Lian, H. Zhu et al., "A systematic, integrated study on the neuroprotective effects of hydroxysafflor yellow a revealed by ${ }^{1} \mathrm{H}$ NMR-based metabonomics and the NF- $\kappa \mathrm{B}$ pathway," Evidence-Based Complementary and Alternative Medicine, vol. 2013, Article ID 147362, 14 pages, 2013.

[64] C.-M. Chern, Y.-H. Wang, K.-T. Liou, Y.-C. Hou, C.-C. Chen, and Y.-C. Shen, "2-Methoxystypandrone ameliorates brain function through preserving $\mathrm{BBB}$ integrity and promoting neurogenesis in mice with acute ischemic stroke," Biochemical Pharmacology, vol. 87, no. 3, pp. 502-514, 2014.

[65] T. Yang, S. Sun, T. Wang et al., "Piperlonguminine is neuroprotective in experimental rat stroke," International Immunopharmacology, vol. 23, no. 2, pp. 447-451, 2014.

[66] Z.-J. Liu, W. Liu, L. Liu, C. Xiao, Y. Wang, and J.-S. Jiao, "Curcumin protects neuron against cerebral ischemia-induced inflammation through improving PPAR-gamma function," 
Evidence-Based Complementary and Alternative Medicine, vol. 2013, Article ID 470975, 10 pages, 2013.

[67] D. Xiong, Y. Deng, B. Huang et al., "Icariin attenuates cerebral ischemia-reperfusion injury through inhibition of inflammatory response mediated by NF- $\kappa \mathrm{B}, \mathrm{PPAR} \alpha$ and PPAR $\gamma$ in rats," International Immunopharmacology, vol. 30, pp. 157-162, 2016.

[68] L. Yu, C. Chen, L.-F. Wang et al., "Neuroprotective effect of kaempferol glycosides against brain injury and neuroinflammation by inhibiting the activation of NF- $\kappa \mathrm{B}$ and STAT3 in transient focal stroke," PLoS ONE, vol. 8, no. 2, Article ID e55839, 2013.

[69] X.-P. Huang, H. Ding, J.-D. Lu, Y.-H. Tang, B.-X. Deng, and C.Q. Deng, "Effects of the combination of the main active components of Astragalus and Panax notoginseng on inflammation and apoptosis of nerve cell after cerebral ischemia-reperfusion," The American Journal of Chinese Medicine, vol. 43, no. 7, pp. 14191438, 2015.

[70] L. Li, H. Li, and M. Li, "Curcumin protects against cerebral ischemia-reperfusion injury by activating JAK2/STAT3 signaling pathway in rats," International Journal of Clinical and Experimental Medicine, vol. 8, no. 9, pp. 14985-14991, 2015.

[71] T.-K. Kao, C.-Y. Chang, Y.-C. Ou et al., "Tetramethylpyrazine reduces cellular inflammatory response following permanent focal cerebral ischemia in rats," Experimental Neurology, vol. 247, pp. 188-201, 2013.

[72] H. Könnecke and I. Bechmann, "The role of microglia and matrix metalloproteinases involvement in neuroinflammation and gliomas," Clinical and Developmental Immunology, vol. 2013, Article ID 914104, 15 pages, 2013.

[73] T. Shichita, R. Sakaguchi, M. Suzuki, and A. Yoshimura, "Postischemic inflammation in the brain," Frontiers in Immunology, vol. 3, article 132, 2012.

[74] X. Dong, Y.-N. Song, W.-G. Liu, and X.-L. Guo, "MMP-9, a potential target for cerebral ischemic treatment," Current Neuropharmacology, vol. 7, no. 4, pp. 269-275, 2009.

[75] A. M. Romanic, R. F. White, A. J. Arleth, E. H. Ohlstein, and F. C. Barone, "Matrix metalloproteinase expression increases after cerebral focal ischemia in rats: inhibition of matrix metalloproteinase-9 reduces infarct size," Stroke, vol. 29, no. 5, pp. 1020-1030, 1998.

[76] S. E. Lakhan, A. Kirchgessner, D. Tepper, and A. Leonard, "Matrix metalloproteinases and blood-brain barrier disruption in acute ischemic stroke," Frontiers in Neurology, vol. 4, article 32, 2013.

[77] Y.-M. Zhang, H. Xu, H. Sun, S.-H. Chen, and F.-M. Wang, "Electroacupuncture treatment improves neurological function associated with regulation of tight junction proteins in rats with cerebral ischemia reperfusion injury," Evidence-Based Complementary and Alternative Medicine, vol. 2014, Article ID 989340, 10 pages, 2014.

[78] H. Jiao, Z. Wang, Y. Liu, P. Wang, and Y. Xue, "Specific role of tight junction proteins claudin-5, occludin, and ZO-1 of the blood-brain barrier in a focal cerebral ischemic insult," Journal of Molecular Neuroscience, vol. 44, no. 2, pp. 130-139, 2011.

[79] R. A. Taylor and L. H. Sansing, "Microglial responses after ischemic stroke and intracerebral hemorrhage," Clinical and Developmental Immunology, vol. 2013, Article ID 746068, 10 pages, 2013.

[80] R. Barakat and Z. Redzic, "Differential cytokine expression by brain microglia/macrophages in primary culture after oxygen glucose deprivation and their protective effects on astrocytes during anoxia," Fluids and Barriers of the CNS, vol. 12, article 6, 2015.

[81] Y.-C. Wang, S. Lin, and Q.-W. Yang, "Toll-like receptors in cerebral ischemic inflammatory injury," Journal of Neuroinflammation, vol. 8, article 134, 2011.

[82] Y. Wang, P. Ge, and Y. Zhu, "TLR2 and TLR4 in the brain injury caused by cerebral ischemia and reperfusion," Mediators of Inflammation, vol. 2013, Article ID 124614, 8 pages, 2013.

[83] X.-K. Tu, W.-Z. Yang, S.-S. Shi et al., "Spatio-temporal distribution of inflammatory reaction and expression of TLR2/4 signaling pathway in rat brain following permanent focal cerebral ischemia," Neurochemical Research, vol. 35, no. 8, pp. 1147-1155, 2010.

[84] A. Maddahi, L. S. Kruse, Q.-W. Chen, and L. Edvinsson, "The role of tumor necrosis factor- $\alpha$ and TNF- $\alpha$ receptors in cerebral arteries following cerebral ischemia in rat," Journal of Neuroinflammation, vol. 8, article 107, 2011.

[85] Q. Hua, X.-L. Zhu, P.-T. Li et al., "The inhibitory effects of cholalic acid and hyodeoxycholalic acid on the expression of TNF $\alpha$ and IL-1 $\beta$ after cerebral ischemia in rats," Archives of Pharmacal Research, vol. 32, no. 1, pp. 65-73, 2009.

[86] W. Chadwick, T. Magnus, B. Martin, A. Keselman, M. P. Mattson, and S. Maudsley, "Targeting TNF- $\alpha$ receptors for neurotherapeutics," Trends in Neurosciences, vol. 31, no. 10, pp. 504-511, 2008.

[87] A. Maddahi and L. Edvinsson, "Cerebral ischemia induces microvascular pro-inflammatory cytokine expression via the MEK/ERK pathway," Journal of Neuroinflammation, vol. 7, article 14, 2010.

[88] H. Boutin, R. A. LeFeuvre, R. Horai, M. Asano, Y. Iwakura, and N. J. Rothwell, "Role of IL- $1 \alpha$ and IL- $1 \beta$ in ischemic brain damage," The Journal of Neuroscience, vol. 21, no. 15, pp. 5528$5534,2001$.

[89] G. P. Schielke, G.-Y. Yang, B. D. Shivers, and A. L. Betz, "Reduced ischemic brain injury in interleukin- $\beta$ converting enzyme- deficient mice," Journal of Cerebral Blood Flow and Metabolism, vol. 18, no. 2, pp. 180-185, 1998.

[90] K. N. Murray, A. R. Parry-Jones, and S. M. Allan, "Interleukin-1 and acute brain injury," Frontiers in Cellular Neuroscience, vol. 9, article 18, 2015.

[91] D. Acalovschi, T. Wiest, M. Hartmann et al., "Multiple levels of regulation of the interleukin-6 system in stroke," Stroke, vol. 34, no. 8, pp. 1864-1869, 2003.

[92] E. Tarkowski, L. Rosengren, C. Blomstrand et al., "Early intrathecal production of interleukin-6 predicts the size of brain lesion in stroke," Stroke, vol. 26, no. 8, pp. 1393-1398, 1995.

[93] T. Yamashita, K. Sawamoto, S. Suzuki et al., "Blockade of interleukin-6 signaling aggravates ischemic cerebral damage in mice: possible involvement of Stat 3 activation in the protection of neurons," Journal of Neurochemistry, vol. 94, no. 2, pp. 459468, 2005.

[94] S. A. Loddick, A. V. Turnbull, and N. J. Rothwell, "Cerebral interleukin-6 is neuroprotective during permanent focal cerebral ischemia in the rat," Journal of Cerebral Blood Flow \& Metabolism, vol. 18, no. 2, pp. 176-179, 1998.

[95] M. Hedtjärn, A.-L. Leverin, K. Eriksson, K. Blomgren, C. Mallard, and H. Hagberg, "Interleukin-18 involvement in hypoxicischemic brain injury," The Journal of Neuroscience, vol. 22, no. 14, pp. 5910-5919, 2002.

[96] F. M. Domac and H. Misirli, "The role of neutrophils and interleukin-8 in acute ischemic stroke," Neurosciences, vol. 13, no. 2, pp. 136-141, 2008. 
[97] S. Jander, M. Schroeter, and G. Stoll, "Interleukin-18 expression after focal ischemia of the rat brain: association with the latestage inflammatory response," Journal of Cerebral Blood Flow \& Metabolism, vol. 22, no. 1, pp. 62-70, 2002.

[98] K. L. Lambertsen, R. Gregersen, M. Meldgaard et al., "A role for interferon-gamma in focal cerebral ischemia in mice," Journal of Neuropathology and Experimental Neurology, vol. 63, no. 9, pp. 942-955, 2004.

[99] C. Marie, C. Pitton, C. Fitting, and J.-M. Cavaillon, "Regulation by anti-inflammatory cytokines (IL-4, IL-10, IL-13, TGF $\beta$ ) of interleukin- 8 production by LPS- and/ or TNF $\alpha$-activated human polymorphonuclear cells," Mediators of Inflammation, vol. 5, no. 5, pp. 334-340, 1996.

[100] X. Liu, J. Liu, S. Zhao et al., "Interleukin-4 is essential for microglia/macrophage M2 polarization and long-term recovery after cerebral ischemia," Stroke, vol. 47, no. 2, pp. 498-504, 2016.

[101] N. Liu, R. Chen, H. Du, J. Wang, Y. Zhang, and J. Wen, "Expression of IL-10 and TNF- $\alpha$ in rats with cerebral infarction after transplantation with mesenchymal stem cells," Cellular and Molecular Immunology, vol. 6, no. 3, pp. 207-213, 2009.

[102] X. Zhao, H. Wang, G. Sun, J. Zhang, N. J. Edwards, and J. Aronowski, "Neuronal interleukin-4 as a modulator of microglial pathways and ischemic brain damage," The Journal of Neuroscience, vol. 35, no. 32, pp. 11281-11291, 2015.

[103] L.-S. Chu, S.-H. Fang, Y. Zhou et al., "Minocycline inhibits 5-lipoxygenase activation and brain inflammation after focal cerebral ischemia in rats," Acta Pharmacologica Sinica, vol. 28, no. 6, pp. 763-772, 2007.

[104] D. A. Ridder and M. Schwaninger, "NF- $\kappa$ B signaling in cerebral ischemia," Neuroscience, vol. 158, no. 3, pp. 995-1006, 2009.

[105] A. Oeckinghaus and S. Ghosh, "The NF-kappaB family of transcription factors and its regulation," Cold Spring Harbor Perspectives in Biology, vol. 1, no. 4, article a000034, 2009.

[106] F. Wan and M. J. Lenardo, "Specification of DNA binding activity of NF-kappaB proteins," Cold Spring Harbor Perspectives in Biology, vol. 1, no. 4, Article ID a000067, 2009.

[107] R. Berti, A. J. Williams, J. R. Moffett et al., "Quantitative real-time RT-PCR analysis of inflammatory gene expression associated with ischemia-reperfusion brain injury," Journal of Cerebral Blood Flow and Metabolism, vol. 22, no. 9, pp. 10681079, 2002.

[108] M. Jiang, J. Li, Q. Peng et al., "Neuroprotective effects of bilobalide on cerebral ischemia and reperfusion injury are associated with inhibition of pro-inflammatory mediator production and down-regulation of JNK1/2 and p38 MAPK activation," Journal of Neuroinflammation, vol. 11, article 167, pp. 1-17, 2014.

[109] L. Wang, Z. Li, X. Zhang et al., "Protective effect of shikonin in experimental ischemic stroke: attenuated TLR4, p-p38MAPK, NF- $\kappa \mathrm{B}$, TNF- $\alpha$ and MMP-9 expression, up-regulated claudin5 expression, ameliorated BBB permeability," Neurochemical Research, vol. 39, no. 1, pp. 97-106, 2014.

[110] H. Liu, X. Wei, L. Kong et al., "NOD2 is involved in the inflammatory response after cerebral ischemia-reperfusion injury and triggers NADPH oxidase 2-derived reactive oxygen species," International Journal of Biological Sciences, vol. 11, no. 5, pp. 525535, 2015.

[111] J.-H. Yi, S.-W. Park, R. Kapadia, and R. Vemuganti, "Role of transcription factors in mediating post-ischemic cerebral inflammation and brain damage," Neurochemistry International, vol. 50, no. 7-8, pp. 1014-1027, 2007.

[112] S. Dziennis and N. J. Alkayed, "Role of signal transducer and activator of transcription 3 in neuronal survival and regeneration," Reviews in the Neurosciences, vol. 19, no. 4-5, pp. 341-361, 2008.

[113] S. Dziennis, T. Jia, O. K. Rønnekleiv, P. D. Hurn, and N. J. Alkayed, "Role of signal transducer and activator of transcription-3 in estradiol-mediated neuroprotection," The Journal of Neuroscience, vol. 27, no. 27, pp. 7268-7274, 2007.

[114] X. Wang, Q. Liu, A. Ihsan et al., "JAK/STAT pathway plays a critical role in the proinflammatory gene expression and apoptosis of RAW264.7 cells induced by trichothecenes as don and T-2 toxin," Toxicological Sciences, vol. 127, no. 2, pp. 412-424, 2012.

[115] C. Schindler, D. E. Levy, and T. Decker, "JAK-STAT signaling: from interferons to cytokines," The Journal of Biological Chemistry, vol. 282, no. 28, pp. 20059-20063, 2007.

[116] C. Lei, J. Deng, B. Wang et al., "Reactive oxygen species scavenger inhibits STAT3 activation after transient focal cerebral ischemia-reperfusion injury in rats," Anesthesia \& Analgesia, vol. 113, no. 1, pp. 153-159, 2011.

[117] H. Zhu, L. Zou, J. Tian, G. Du, and Y. Gao, "SMND-309, a novel derivative of salvianolic acid $\mathrm{B}$, protects rat brains ischemia and reperfusion injury by targeting the JAK2/STAT3 pathway," European Journal of Pharmacology, vol. 714, no. 1-3, pp. 23-31, 2013.

[118] L. Li, X. Zhang, L. Cui et al., "Ursolic acid promotes the neuroprotection by activating Nrf2 pathway after cerebral ischemia in mice," Brain Research, vol. 1497, pp. 32-39, 2013.

[119] M. Li, X. Zhang, L. Cui et al., "The neuroprotection of oxymatrine in cerebral ischemia/reperfusion is related to nuclear factor erythroid 2-related factor 2 (Nrf2)-mediated antioxidant response: role of Nrf2 and hemeoxygenase-1 expression," Biological and Pharmaceutical Bulletin, vol. 34, no. 5, pp. 595-601, 2011.

[120] Y. Dong, H. D. Liu, R. Zhao et al., "Ischemia activates JNK/cJun/AP-1 pathway to up-regulate 14-3-3 $\gamma$ in astrocyte," Journal of Neurochemistry, vol. 109, supplement 1, pp. 182-188, 2009. 


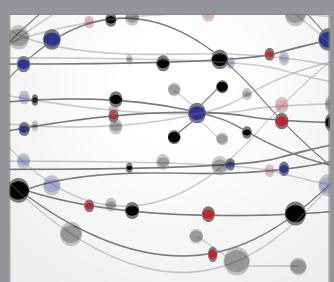

The Scientific World Journal
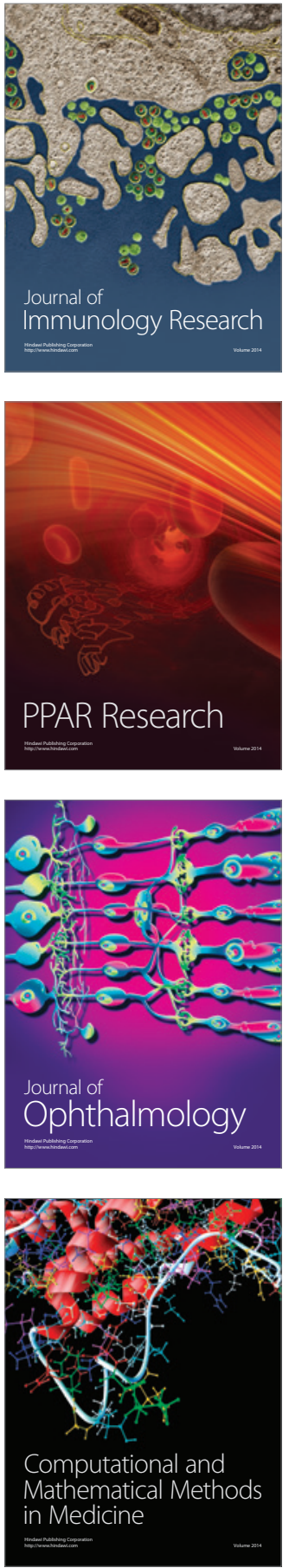

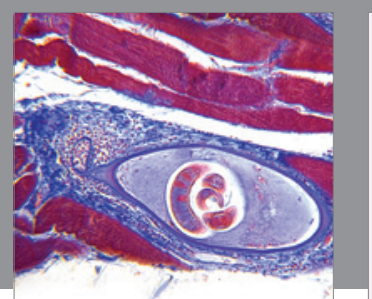

Gastroenterology Research and Practice

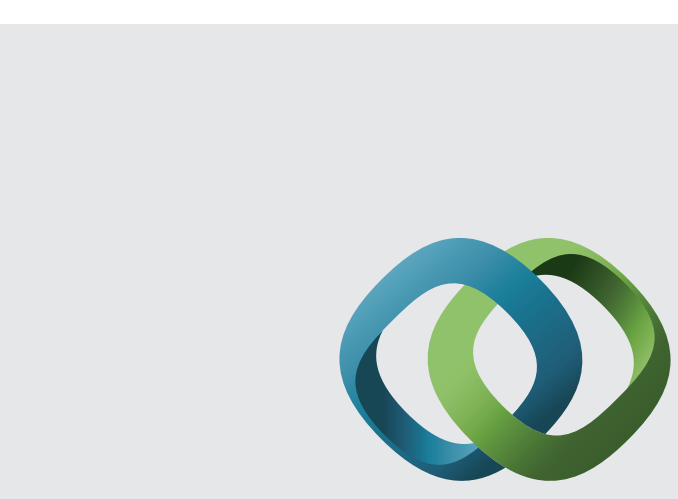

\section{Hindawi}

Submit your manuscripts at

http://www.hindawi.com
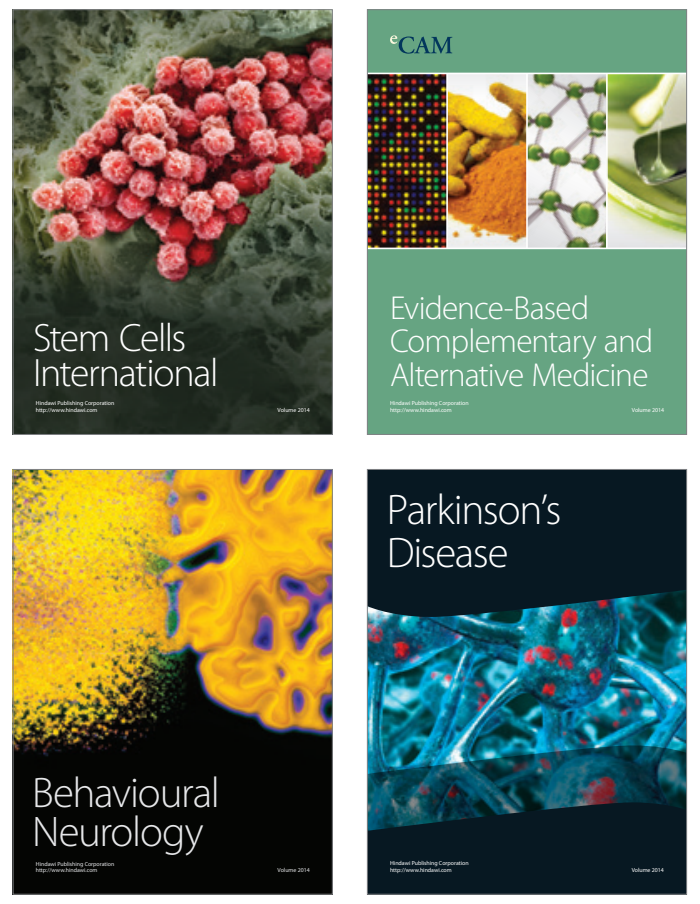
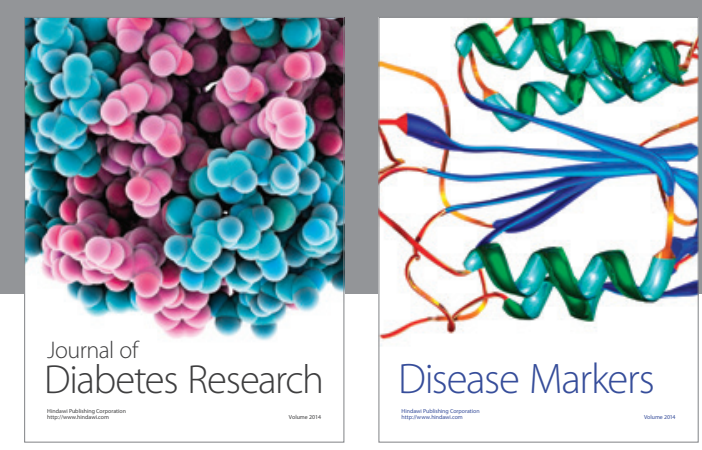

Disease Markers
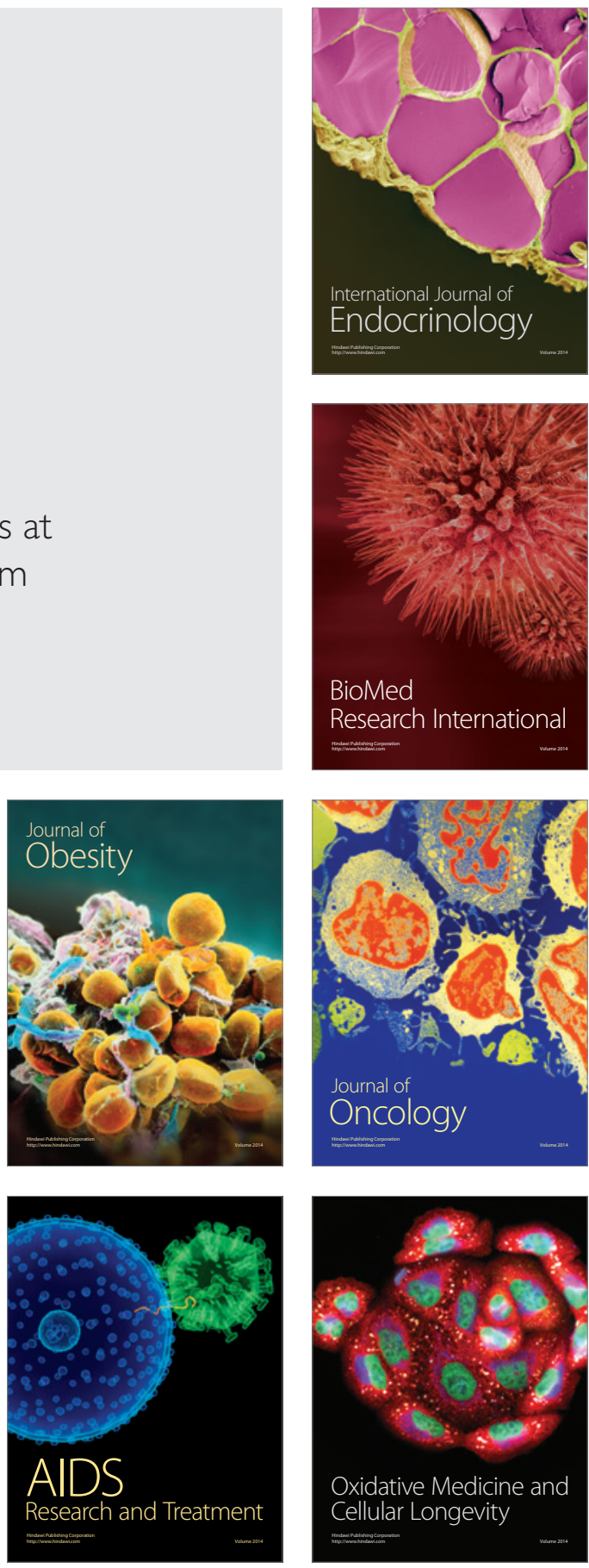